\title{
Uso de modelos de primatas neotropicais para pesquisa em malária: um histórico dos 25 anos de colaboração entre o Laboratório de Pesquisa em Malária (IOC, Fiocruz) e o Centro Nacional de Primatas (IEC, SVS)
}

\author{
Neotropical primate models for malaria research: 25 years of collaboration between \\ Laboratory of Malaria Research (IOC, Fiocruz) and Centro Nacional de Primatas (IEC, SVS)
}

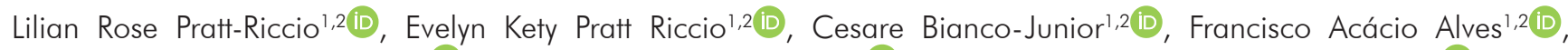 \\ Bárbara de Oliveira Baptista1,2 (D), Paulo Renato Rivas Totino ${ }^{1,2}$, José Augusto Pereira Carneiro Muniz ${ }^{3}$ (D), Paulo \\ Henrique Gomes de Castro3(iD), Leonardo José de Moura Carvalho1,2 (iD, Cláudio Tadeu Daniel-Ribeiro1,2 (iD) \\ ' Fundação Oswaldo Cruz, Instituto Oswaldo Cruz, Laboratório de Pesquisa em Malária, Rio de Janeiro, Rio de Janeiro, Brasil \\ 2 Fundação Oswaldo Cruz, Centro de Pesquisa, Diagnóstico e Treinamento em Malária, Rio de Janeiro, Rio de Janeiro, Brasil \\ ${ }_{3}^{3}$ Instituto Evandro Chagas/SVS/MS, Centro Nacional de Primatas, Ananindeua, Pará, Brasil
}

\begin{abstract}
RESUMO
A malária continua sendo um dos principais problemas globais de saúde pública, sendo responsável pela morte de 409.000 pessoas anualmente, principalmente devido à infecção por Plasmodium falciparum. Assim, o desenvolvimento de uma vacina tem sido uma das prioridades de pesquisa para o enfrentamento desse problema. Não existe vacina licenciada contra a malária e, embora mais de 30 antígenos tenham sido identificados como candidatos vacinais, nenhum deles gerou uma perspectiva sólida de que uma vacina possa estar disponível nos próximos anos. Torna-se fundamental a pesquisa de candidatos vacinais mais imunogênicos, eficazes e seguros. Os primatas neotropicais dos gêneros Saimiri e Aotus são os modelos recomendados para estudos experimentais em malária, visto que podem ser infectados por plasmódios humanos. O Laboratório de Pesquisa em Malária (LabMal) da Fundação Oswaldo Cruz estuda os mecanismos de defesa e doença na malária e utiliza os modelos Saimiri e Aotus para a avaliação pré-clínica de antígenos candidatos à vacina e estudos de mecanismos de aquisição de imunidade e fisiopatogenia da malária. Para a realização dos estudos, o LabMal estabeleceu uma parceria com o Centro Nacional de Primatas (CENP) do Instituto Evandro Chagas, que resultou na ampliação das colônias de Saimiri sciureus, colocando o CENP entre as raras instituições no mundo que dispõem desse recurso para pesquisa. $\bigcirc$ presente trabalho é um retrospecto dos resultados obtidos durante 25 anos de parceria entre o LabMal e o CENP na utilização de primatas Saimiri e Aotus como modelos de estudo para pesquisa e desenvolvimento de uma vacina antimalárica.
\end{abstract}

Palavras-chave: Malária; Plasmodium falciparum; Modelos Animais; Experimentação animal; Saimiri; Aotus.

\begin{abstract}
Malaria remains a significant public health problem and, responsible for 409,000 deaths annually, mainly due to infection by Plasmodium falciparum. Thus, the development of an effective vaccine has been a research priority to address the problem. There is no licensed vaccine, and although more than 30 antigens have been identified as candidates, none of them has yet generated a solid prospect that an effective vaccine may be available in the coming years. Therefore, it is essential to search for new, more immunogenic, more effective and safer vaccine candidates. The neotropical, non-human primates (NHP) of the genera Saimiri and Aotus are recommended as experimental models for the study of human malaria because these animals can be infected with the Plasmodium that infect humans. The Laboratory of Malaria Research (LabMal, Fiocruz) studies the mechanisms of defense and disease in malaria and uses the Saimiri and Aotus experimental models for preclinical evaluation of antimalarial vaccine candidates and for conducting studies of immunity acquisition mechanisms and physiopathogenesis of malaria. To carry out the studies, LabMal established a partnership with the Centro Nacional de Primatas (CENP) of the Instituto Evandro Chagas, which resulted in the expansion of Saimiri sciureus colonies, placing CENP among the few institutions in the world that have this resource for malaria research. The present paper is a retrospective of the results obtained during 25 years of partnership between LabMal and CENP in the use of Saimiri and Aotus as study models for research and development of an antimalarial vaccine.
\end{abstract}

Keywords: Malaria; Plasmodium falciparum; Animal Models; Saimiri; Aotus.

\section{Correspondência / Correspondence:}

Cláudio Tadeu Daniel-Ribeiro

Fundação Oswaldo Cruz, Laboratório de Pesquisa em Malária

Av. Brasil, 4365. Bairro: Manguinhos. CEP: 21040-360 - Rio de Janeiro, Rio de Janeiro, Brasil. Tel.: +55 (21) 3865-8145

E-mail:malaria@fiocruz.br 


\section{INTRODUÇÃO}

A malária é indiscutivelmente a parasitose mais importante em humanos ainda nos dias de hoje, e apesar dos avanços no seu controle, fatores como a demora no diagnóstico, a resistência dos parasitos aos antimaláricos e a resistência do inseto vetor aos inseticidas dificultam o controle da doença. Assim, a malária continua sendo um dos principais problemas globais de saúde pública, estando presente em 91 países das regiões tropicais e subtropicais do mundo, pondo em risco cerca de $61 \%$ da população mundial. Sete espécies de Plasmodium (Figura 1) causam doenças em humanos: Plasmodium falciparum, Plasmodium vivax, Plasmodium ovale, Plasmodium malariae, Plasmodium knowlesi, Plasmodium cynomolgi e Plasmodium simium. Globalmente, P. falciparum e $P$. vivax são responsáveis pela maioria dos $\operatorname{casos}^{1,2}$. Segundo estimativas da Organização Mundial da Saúde (OMS), no ano de 2019, foram registrados 229 milhões de casos no mundo com 409.000 mortes, a maioria em crianças menores de 5 anos de idade ${ }^{2}$. As mortes por malária são, em sua grande maioria, de indivíduos que contraem a infecção por $P$. falciparum (99,7\%). A infecção por P. knowlesi resulta em uma malária de evolução muito rápida, que pode ser fatal com bastante frequência ${ }^{3,4,5,6}$.

Em 2019, o Brasil registrou cerca de 22\% dos casos de malária das Américas², tendo sido notificados 155.638 casos, quase todos $(99,6 \%)$ na Região Amazônica, área endêmica da doença, que inclui os estados do Acre, Amapá, Amazonas, Maranhão, Mato Grosso, Pará, Rondônia, Roraima e Tocantins. Nos outros estados, os casos ( $\sim 0,4 \%$ do total) são frequentemente importados da Região Amazônica ou de outros países onde ocorre a transmissão. A proporção de casos importados/casos autóctones, em torno de 9/1, diminuiu nos últimos anos depois do aumento da prevalência de casos autóctones de transmissão zoonótica de P. simium em regiões de Mata Atlântica no sudeste brasileiro ${ }^{7}$.

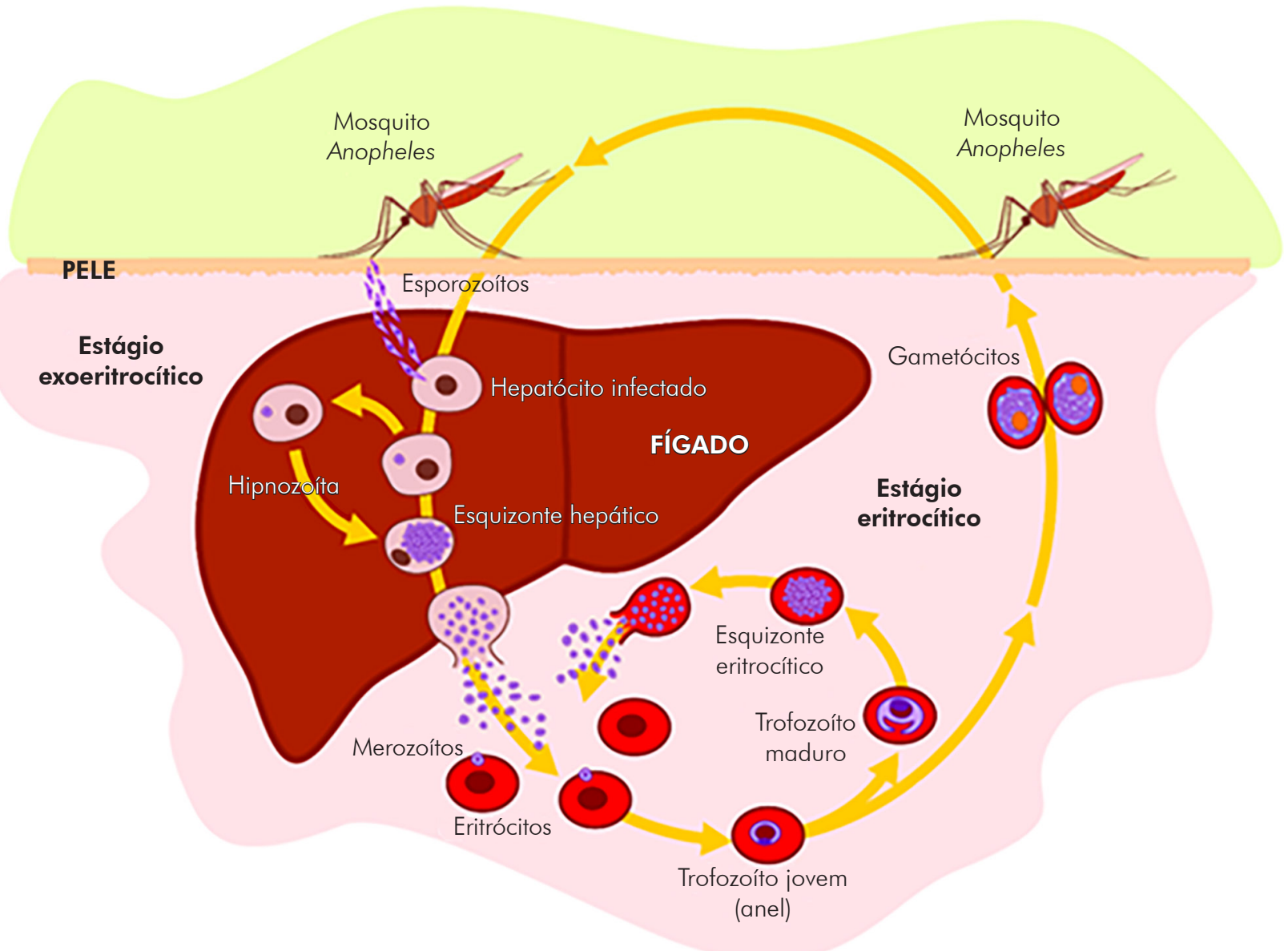

Fonte: Adaptado de Lima-Junior JC, Pratt-Riccio LR. Major histocompatibility complex and malaria: focus on Plasmodium vivax infection. Front Immunol. 2016;7:13. Doi: 10.3389/fimmu.2016.00013.

A infecção no homem se inicia quando fêmeas do mosquito Anopheles, durante o repasto sanguíneo, inoculam na pele os esporozoítos acumulados em suas glândulas salivares. Essas formas se movem ativamente até encontrarem os vasos linfáticos ou sanguíneos, vias pelas quais chegam ao fígado, onde invadem os hepatócitos, iniciando a fase exoeritrocítica. Os esporozoítas se diferenciam em esquizontes hepáticos com milhares de merozoítos que são liberados na corrente sanguínea e são capazes de invadir eritrócitos. No ciclo do Plasmodium vivax e do Plasmodium ovale, nem todos os esporozoítos que infectam os hepatócitos entram em processo de esquizogonia. Ao invés disso, eles se desenvolvem em formas hepáticas latentes, chamadas hipnozoítos, permitindo as recaídas tardias da doença. A invasão dos merozoítos nos eritrócitos dá início ao ciclo eritrocítico da infecção, fase na qual ocorrem os sintomas clínicos da malária. Dentro do eritrócito, os merozoítos se diferenciam em trofozoítos jovens e maduros, que se multiplicam, dando origem a esquizontes repletos de merozoítos sanguíneos. Com o amadurecimento do esquizonte, ocorre a lise dos eritrócitos, liberando os merozoítos sanguíneos, que invadirão novos eritrócitos. Após alguns ciclos, alguns merozoítos se diferenciam em formas eritrocíticas sexuadas, os gametócitos femininos (macrogametócitos) e os gametócitos masculinos (microgametócitos), que, ao serem ingeridos por um mosquito durante um repasto sanguíneo, dão início ao ciclo esporogônico. Nessa fase, após subsequentes diferenciações celulares, os esporozoítos que se desenvolvem atingem as glândulas salivares do inseto, possibilitando continuidade do ciclo parasitário.

Figura 1 - Ciclo evolutivo do Plasmodium 
O controle da malária depende do combate ao vetor e do diagnóstico e tratamento oportunos ${ }^{2}$. No entanto, a eficácia das intervenções está sob ameaça devido à crescente resistência dos plasmódios aos antimaláricos e dos vetores aos inseticidas atualmente disponíveis, além do surgimento de isolados resistentes aos derivados de artemisinina $8,9,10,11,12,13$. Assim, o desenvolvimento de uma vacina eficaz contra a malária tem sido uma das prioridades de pesquisa para o enfrentamento desse problema, e a OMS definiu o objetivo ambicioso de licenciar uma vacina que seja pelo menos $75 \%$ eficaz contra a malária clínica até $2030^{14}$.

Não existe ainda vacina licenciada disponível contra o P. falciparum, espécie que está associada às formas mais graves e letais da doença ${ }^{15,16}$. Embora mais de 30 antígenos tenham sido identificados como candidatos à vacina, muitos dos quais já foram testados em ensaios pré-clínicos e clínicos até de fase III, até o momento nenhum deles gerou a perspectiva sólida de que uma vacina verdadeiramente eficaz possa estar disponível nos próximos anos ${ }^{17,18,19,20}$.

Criada em 1987, a RTS,S/ASO1 é a mais avançada vacina contra a malária por P. falciparum em desenvolvimento. A RTS,S/ASO1 está atualmente em ensaio clínico de fase III e, em 2019, começou a implementação piloto em países endêmicos para avaliar a segurança e o impacto na mortalidade em populações de crianças no Gana, Quênia e Malawi ${ }^{21,22}$. Entretanto, em vários ensaios clínicos realizados, a vacina mostrou proteção parcial em adultos, crianças e bebês, além de apresentar uma variação preocupante na eficácia contra a malária clínica $(12,5 \% \text { a } 86 \%)^{23,24,25,26,27,28}$. Além disso, testes conduzidos em fase III, em sete países subsaarianos, mostraram eficácia variável da vacina em 11 locais $(40-77 \%)^{28,29}$. Portanto, ainda é fundamental a pesquisa de novos candidatos vacinais mais imunogênicos, mais eficazes e seguros.

Para se avaliar imunogenicidade, inocuidade e capacidade protetora de uma candidata vacinal contra qualquer patógeno humano, é necessária a utilização de uma variedade de modelos animais. Em geral, os primeiros ensaios são feitos em animais de laboratório de pequeno porte, como camundongos, ratos e coelhos, pela facilidade de obtenção de quantidade razoável de espécimes e material biológico a preços acessíveis. Entretanto, resultados obtidos nesses modelos podem não refletir a situação no homem e não são, portanto, facilmente extrapoláveis.

Pesquisas envolvendo primatas não humanos (PNH) têm desempenhado um papel crítico em muitos dos avanços médicos e científicos nas últimas décadas. PNH são usados devido às semelhanças com os humanos em termos de fisiologia, neuroanatomia, reprodução, desenvolvimento, cognição e complexidade social. Essas semelhanças sugerem que os dados obtidos em PNH são mais válidos em comparação com outros modelos $30,31,32,33,34$.
Pela sua proximidade filogenética com o homem, os grandes PNH Hominoidea (chimpanzés, gorilas, orangotangos e gibões) seriam os ideais para estudos pré-clínicos de vacinas ${ }^{31,35}$. Entretanto, a dificuldade de obtenção de tais animais para experimentação se deve ao fato de que eles: 1) estão em sua maioria ameaçados na natureza; 2) são de grande porte e possuem baixa taxa de fecundidade e longo ciclo de vida e; 3) têm alto custo de manutenção em cativeiro, acarretando impedimentos muitas vezes intransponíveis para seu uso experimental. Uma melhor opção seria a utilização de macacos do Velho Mundo, como o Rhesus (Macaca mulatta), o Cynomolgus (Macaca nemestrina) ou os macacos verdes africanos (Cercopithecus aethiops). Todavia, apesar de serem mais acessíveis que os anteriores, também são animais de porte e longevidade consideráveis, sendo cara a sua manutenção.

Os primatas do Novo Mundo são uma opção bem mais razoável para estudos vacinais. Em geral, esses animais são de pequeno porte e não estão, em sua maioria, ameaçados na natureza. Entre as espécies utilizadas em pesquisa biomédica, pode-se citar os dos gêneros Aotus (macaco-da-noite), Saimiri (macaco-de-cheiro), Cebus (macaco prego) e variedades de saguis, como o Callithrix jacchus (mico-estrela).

Os primatas neotropicais dos gêneros Saimiri e Aotus são os modelos recomendados pela OMS para estudos experimentais em malária, especialmente para estudos vacinais ${ }^{35,36,37,38}$. A principal vantagem dos primatas neotropicais Saimiri e Aotus - animais de muito menor porte e abundantes na natureza - é que podem ser infectados, sob determinadas condições, por plasmódios humanos como o P. falciparum, O P. vivax e o P. malariae. Isso permite a realização de estudos capazes de trazer informações impossíveis de serem obtidas em outros modelos. Por exemplo, os modelos de malária murina utilizam plasmódios próprios de roedores, com suas características específicas. Assim, apesar de informativos, esses sistemas estão muito distantes do que podem ser as interações de um parasito humano com seu hospedeiro. Desse modo, a possibilidade de estudar o próprio parasito-alvo em um animal filogeneticamente próximo ao homem traz vantagens óbvias. A susceptibilidade à infecção por plasmódios humanos traz outra vantagem aos modelos Saimiri e Aotus, pois permite que, em ensaios vacinais, além das avaliações clássicas de imunogenicidade e inocuidade das formulações-teste, seja possível verificar a capacidade protetora dos candidatos vacinais estudados por meio de experimentos de desafio, o que não é o caso em macacos como o Rhesus, filogeneticamente mais próximo ao homem e também utilizável em estudos de imunogenicidade e inocuidade. Assim, primatas neotropicais vêm sendo usados para a avaliação de potenciais candidatos vacinais e para o estudo da fisiopatologia das formas graves da malária causada por P. falciparum. 
Embora recomendados pela OMS, esses modelos também apresentam desvantagens. Uma das principais limitações é a necessidade de esplenectomia para atingir parasitemias altas e consistentes ${ }^{39}$. A resposta imune contra as formas eritrocíticas do Plasmodium é amplamente mediada por células residentes no baço ${ }^{40,41,42}$ e esse órgão tem papel importante na resposta imune durante a infecção. Portanto, a esplenectomia cirúrgica radical representa uma forte limitação para o teste de vacinas contra a malária, já que as próprias respostas imunológicas que as vacinas pretendem provocar podem ser afetadas pela intervenção.

O Laboratório de Pesquisa em Malária (LabMal) do Instituto Oswaldo Cruz, Fundação Oswaldo Cruz (Fiocruz, Rio de Janeiro, RJ), estuda, desde 1984, os mecanismos de defesa e doença na malária, trabalhando na avaliação de vacinas antimaláricas em primatas não humanos desde 1997. O LabMal tem interesse na exploração dos modelos Saimiri e Aotus não apenas para avaliação pré-clínica de antígenos candidatos à vacina antimalárica, mas também para a condução de estudos de mecanismos de aquisição de imunidade e de fisiopatogenia da malária. Para a realização dos estudos, o LabMal estabeleceu uma parceria com o Centro Nacional de Primatas (CENP), Instituto Evandro Chagas (IEC, Ananindeua, Pará), que resultou, como desdobramento dos projetos, na ampliação das colônias de Saimiri sciureus, colocando o CENP, juntamente com o Departamento de Primatologia do Instituto de Ciência e Tecnologia em Biomodelos (ICTB, Fiocruz, Rio de Janeiro, RJ), entre as raras instituições no mundo que dispõem desse recurso em quantidade e qualidade necessária para apoiar a pesquisa em malária. A ampliação da colônia se operacionalizou à custa de capturas realizadas em parceria entre técnicos da Fiocruz, CENP e Instituto Brasileiro do Meio Ambiente e dos Recursos Naturais
Renováveis. No ICTB, a extensão da colônia deveu-se, sobretudo, à cessão de mais de duas centenas de primatas neotropicais da espécie $S$. sciureus pelo Institut Pasteur de Cayenne (Guiana Francesa).

No presente trabalho, foram descritos os resultados obtidos durante 25 anos de colaboração entre o LabMal e o CENP, na utilização de PNH dos gêneros Saimiri e Aotus como modelos de estudo para a pesquisa e o desenvolvimento de uma vacina antimalárica humana.

\section{DESCRIÇÃO DA SUSCEPTIBILIDADE DE MACACOS AOTUS INFULATUS À INFECÇÃO PELO P. FALCIPARUM}

A espécie Aotus griseimembra, do norte da Colômbia, é altamente susceptível à infecção por Plasmodium nos estágios esporozoíto e eritrocitário ${ }^{43,44}$; porém, a dificuldade na sua obtenção tem levado à avaliação de outras espécies do gênero Aotus como modelos alternativos para estudos experimentais em malária humana. Assim, o LabMal avaliou a susceptibilidade dos primatas neotropicais $A$. infulatus, abundantes na Amazônia brasileira, à infecção experimental por P. falciparum.

Cinco macacos Aotus (dois esplenectomizados e três intactos), foram inoculados com $10^{6}$ hemácias parasitadas por P. falciparum (Pfhp) cepa FVO provenientes de um Aotus doador infectado. Tanto os Aotus esplenectomizados quanto os intactos apresentaram parasitos no sangue a partir do dia três ou quatro. A parasitemia subiu nos dois grupos de modo semelhante nos primeiros dias até atingir valores próximos a $1 \%$ no dia sete (Figura 2), mostrando que tanto os animais intactos quanto os esplenectomizados foram susceptíveis à infecção por $P$. falciparum e podem representar um modelo alternativo para estudos experimentais em malária ${ }^{45}$.

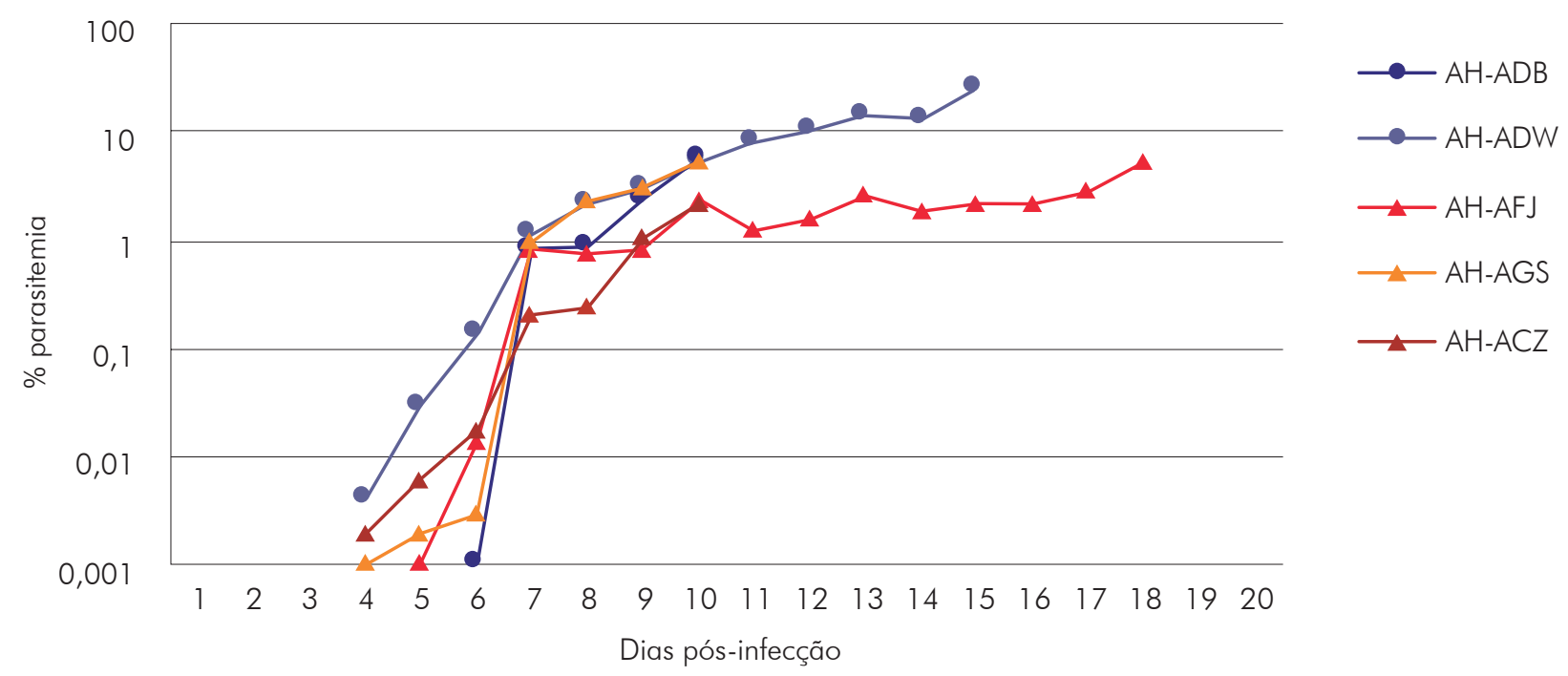

Os macacos foram inoculados com $1 \times 10^{6}$ de hemácias parasitadas por P. falciparum cepa FVO. Esplenectomizados: AH-ADB e AH-ADW; Intactos: AH-AFJ, AH-AGS e AH-ACZ.

Figura 2 - Curso de parasitemia em $A$. infulatus esplenectomizados ou intactos 


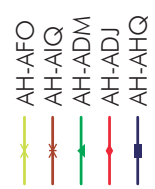

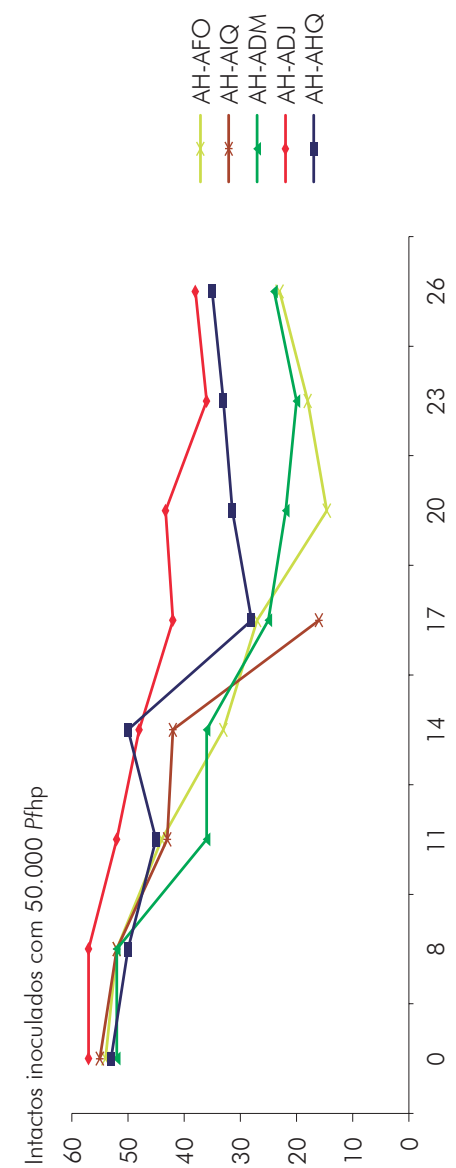

$\infty$
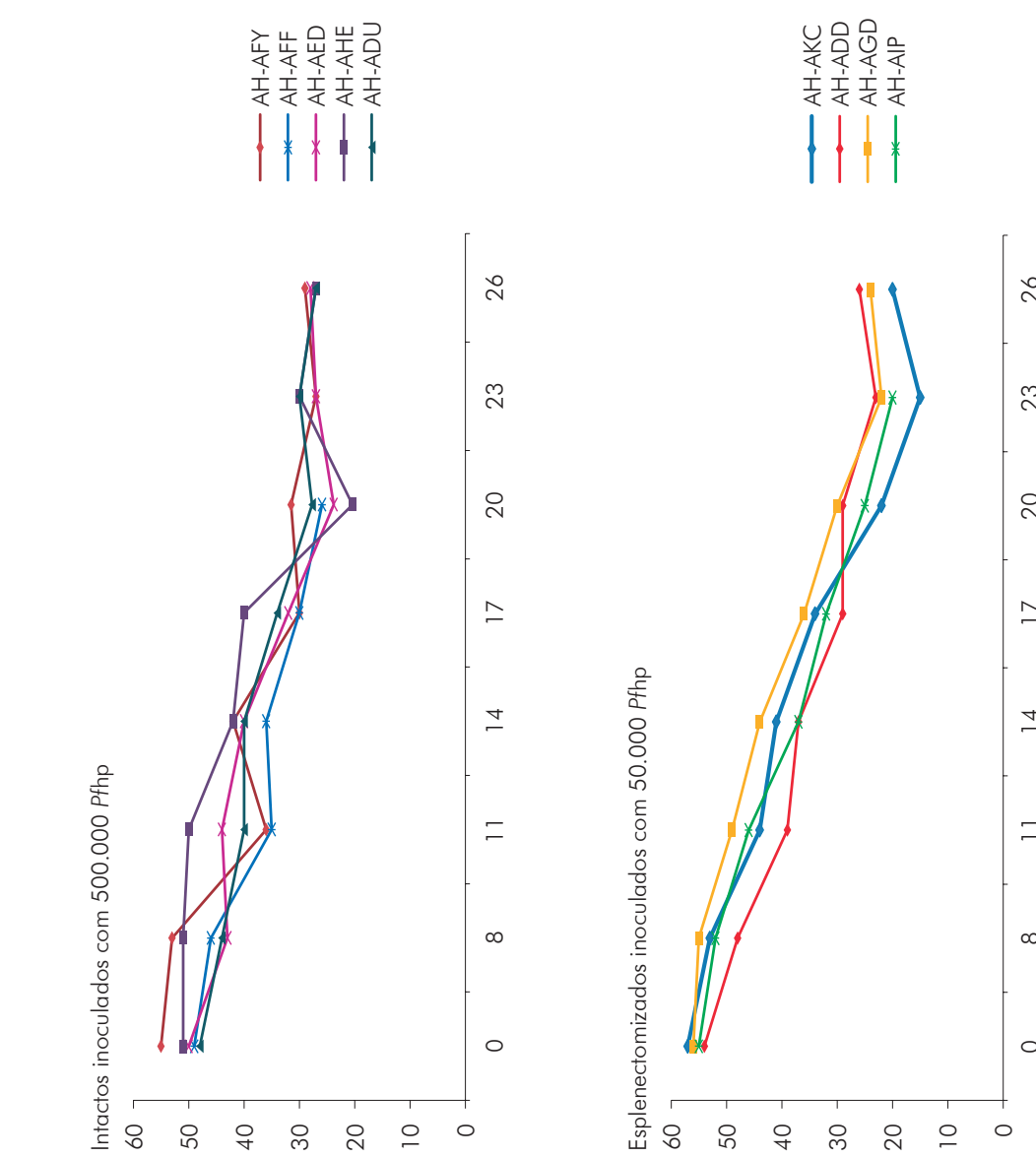

$\frac{1}{0}$
$\frac{a}{0}$
$\frac{9}{0}$
$\frac{0}{0}$
$\frac{5}{5}$
$\frac{0}{0}$
$\frac{0}{2}$
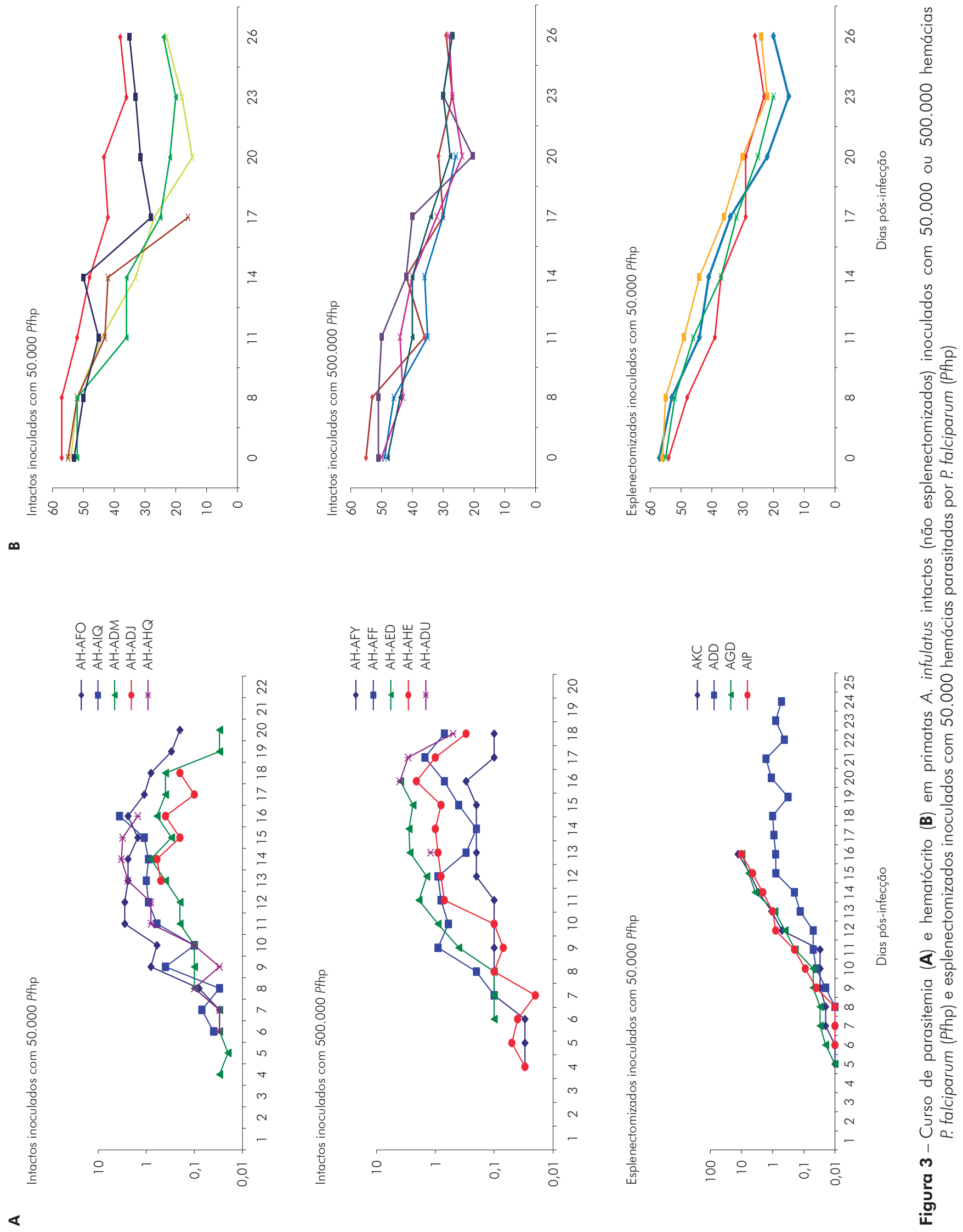
Outro dado importante foi a observação de que os animais esplenectomizados não foram capazes de controlar o crescimento do parasito, desenvolvendo uma alta parasitemia, sendo necessário o tratamento com mefloquina. Por outro lado, os animais não esplenectomizados conseguiram manter a parasitemia em níveis mais baixos por longos períodos, mas desenvolveram uma anemia grave ${ }^{46}$. $\bigcirc$ desenvolvimento dessa complicação, que já foi descrita para outras espécies de Aotus durante a infecção por $P$. falciparum ${ }^{47,48,49}$, faz de $A$. infulatus um modelo potencial não só para ensaios vacinais, mas também para estudos da patogenia da anemia grave. Entretanto, esse experimento utilizou um número restrito de animais, não permitindo conclusões definitivas. Assim, o LabMal avaliou o curso de infecção em $A$. infulatus por formas sanguíneas de P. falciparum, utilizando diferentes inóculos, em um número maior de animais, e a frequência de acometimento de animais por anemia grave decorrente dessa infecção ${ }^{45}$. Quatorze macacos A. infulatus (quatro esplenectomizados e 10 intactos) foram inoculados com Pfhp cepa FVO proveniente de um Aotus doador infectado. $\bigcirc$ grupo de 10 animais intactos foi dividido em dois subgrupos de cinco animais cada e inoculados com 50.000 ou 500.000 Pfhp. Os animais esplenectomizados receberam um inóculo de 50.000 Pfhp. Os Aotus intactos, tanto os que receberam o inóculo de 50.000 Pfhp quanto os que receberam o inóculo de 500.000 Pfhp, mostraram um padrão similar de crescimento parasitário (Figura 3A). Apesar dos animais terem conseguido controlar a parasitemia, nove dos 10 macacos apresentaram redução de 45 a $72 \%$ no valor do hematócrito (Figura 3B). Três dos quatro Aotus esplenectomizados inoculados com 50.000 Pfhp não conseguiram controlar a parasitemia (Figura 3A) e apresentaram uma queda de mais de $50 \%$ nos valores do hematócrito inicial (Figura 3B).

Depois de avaliar os eventos resultantes de uma infecção primária, procurou-se avaliar também as características de infecções secundárias. Assim, três meses após o tratamento da primeira infecção, todos os animais receberam $10^{6} \mathrm{Pfhp}$. Justifica-se o inóculo elevado ao se considerar que os animais estariam semi-imunes e poderiam estar resistentes a essa infecção secundária. Duas inoculações posteriores com um inóculo menor (10 $10^{5}$ Pfhp) foram efetuadas quatro e dois meses após a segunda e a terceira inoculações, respectivamente. Objetivou-se assim reforçar a imunidade dos animais ao parasito (uma vez que os animais se mostraram bastante resistentes já na segunda inoculação) para posterior obtenção de soro hiperimune para ensaios imunológicos. Os Aotus intactos submetidos a infecções repetidas com parasitos homólogos tornaram-se rapidamente e progressivamente resistentes à infecção e ao desenvolvimento de anemia grave.

Esses dados mostram que o primata neotropical A. infulatus é susceptível ao desenvolvimento de anemia grave devido à infecção por $P$. falciparum, de forma independente da presença do baço ou da parasitemia, tornando-os bons modelos de estudos experimentais em malária humana, especialmente no que diz respeito à patogênese de anemia grave ${ }^{45,46,50}$.

\section{DESENVOLVIMENTO E VALIDAÇÃO DE FERRAMENTAS MOLECULARES PARA ANÁLISE DA RESPOSTA IMUNE DE PRIMATAS AOTUS E SAIMIRI}

Apesar de Aotus e Saimiri serem os modelos mais adequados para estudos em malária, a carência de reagentes comerciais específicos dificulta a avaliação da resposta imune em ensaios pré-clínicos vacinais e o estudo de patogenia da malária, representando uma desvantagem importante na utilização desses modelos. O grupo do LabMal produziu reagentes específicos para análise da resposta humoral, que aumentou enormemente a sensibilidade das medidas realizadas com ensaios de ELISA e de imunofluorescência com soro de Saimiri e Aotus ${ }^{51}$. Com a obtenção de reagentes específicos para análise de resposta humoral, decidiu-se que uma abordagem semelhante poderia ser aplicada ao desenvolvimento de reagentes para análise de resposta celular nesses modelos, uma vez que isso permitiria uma avaliação mais refinada das respostas imunes nesses animais.

Dessa forma, o LabMal se propôs a desenvolver ferramentas moleculares específicas das espécies Saimiri e Aotus e utilizá-las para avaliar a expressão gênica de moléculas relacionadas à resposta imune, tais como citocinas, quimiocinas, marcadores de ativação, diferenciação e morte celular. A disponibilização dessas ferramentas permite uma avaliação mais aprofundada da resposta imune durante imunizações e infecções maláricas experimentais utilizando essas espécies como modelos. E poderá permitir ainda a identificação e a caracterização de processos imunes durante a infecção, por exemplo, de mecanismos que levam à desestruturação de órgãos linfoides com intensa ativação, proliferação e morte celular e pouca diferenciação, fenômenos que podem contribuir para a baixa eficácia da resposta imune na malária. O conhecimento mais aprofundado desses fenômenos em modelos que refletem melhor a infecção humana poderá gerar informações cruciais para a compreensão dos mecanismos de imunopatogenia da malária humana.

Para isso, um painel de 31 moléculas do sistema imune, entre citocinas, quimiocinas, marcadores de ativação celular e de apoptose, foi selecionado: IFN $\gamma$, TNF, LTA, IL-2, IL-6, IL-10, IL-12, IL-3, IL-4, IL-5, IL-8, IL-13, IL-17, IL-18, IL-27, CCL1, CCL2, CCR3, CCR4, CCR5, CCR8, CSF2, CD40, FAS, STAT4, MIF, EPO, TGF $\beta$, TNFRSF1A, BAX e AID ${ }^{52}$. As sequências dos genes humanos correspondentes serviram como molde para o desenho de primers usados na amplificação e no sequenciamento de DNA genômico de Saimiri e Aotus. As sequências, então obtidas, foram usadas como moldes para desenhar primers específicos para o estudo da expressão gênica por meio de reação em cadeia da polimerase (PCR) em tempo real quantitativa (PCR-TRq). Posteriormente, células mononucleares do sangue periférico (PBMC) 
de Aotus e Saimiri foram purificadas e cultivadas para avaliação de cinética e de expressão gênica sob estimulação mitogênica (entre 2 e 18 h). Foram realizadas a extração de RNA e a síntese de cDNA, que foi usado como molde para as reações de PCR-TRq, utilizando-se os iniciadores baseados nas sequências das duas espécies de macacos. Após a escolha do melhor tempo de expressão $(6 \mathrm{~h})$, foi realizado o experimento de infecção em macacos Saimiri e a análise da expressão de citocinas em esplenócitos de macacos primo-infectados sob estímulos mitogênico e antigênico. Dos 31 pares de primers desenhados a partir de genes humanos, 17 foram capazes de amplificar e sequenciar o fragmento gênico correspondente em Saimiri e Aotus. As 17 sequências obtidas foram comparadas com as sequências humanas e de outros primatas não-humanos (Tabela 1). Em alguns casos, graus muito elevados de identidade entre as sequências humana e de Saimiri e Aotus foram observados (acima de 97\%), como TGF $\beta$ e BAX, enquanto outras como IL-3 apresentaram baixa identidade (82\%). Esses dados mostram que, inicialmente, as sequências humanas podem ser usadas como molde para o desenho de primers empregados na amplificação e sequenciamento de genes de macacos Saimiri e Aotus. Entretanto, apesar da estreita relação filogenética existente entre Aotus, Saimiri, outros primatas não-humanos e humanos, as diferenças genômicas existentes são suficientes para restringir ou mesmo impedir o uso de iniciadores baseados em sequências humanas e justificam o esforço de desenvolvimento de ferramentas específicas para os primatas neotropicais. Com base nos dados de sequência obtidos, foram desenhados pares de iniciadores para PCR-TRq para sete das 17 sequências obtidas (IFN- $\gamma$, IL-12, TNF, IL-2, IL-6, IL-10 e LTA). Para validar os iniciadores de PCR-TRq e testar o efeito da ativação celular sobre a indução da transcrição desses genes, PBMC de Saimiri foram cultivadas em presença ou não de mitógenos (ionomicina/fitohemaglutinina - PMA) durante 2, 4, 6, 8,12 e 18 h. Os primers detectaram a presença de transcritos em células estimuladas já com $2 \mathrm{~h}$ de cultivo celular e que os melhores tempos para detecção de transcritos ocorreram entre 6 e 12 h (Figura 4).

De posse de pares de iniciadores funcionais em PCR-TRq, realizou-se um experimento de infecção de seis $S$. sciureus intactos por formas de estágio sanguíneo de $P$. falciparum. Pôde-se observar que o modelo de infecção de animais não esplenectomizados com a cepa FUP de P. falciparum foi viável para indução de parasitemias consistentes, que alcançaram cerca de 10\% com nove a 13 dias de infecção (Figura 5A). Os animais apresentaram uma queda brusca de hematócrito, quadro de anemia grave idêntico ao da malária humana (Figura 5B). Para a realização do experimento de infecção, foram usados seis animais intactos, os quais foram esplenectomizados somente sete, 14 ou 28 dias após a infecção. Em todos os casos, foram feitas paralelamente a esplenectomia e a separação de esplenócitos de um animal-controle. As células esplênicas $\left(2 \times 10^{6}\right.$ células $\left./ \mathrm{mL}\right)$ foram
Tabela 1 - Grau de identidade encontrado entre os primatas Aotus e Saimiri, outros primatas não-humanos e o homem

\begin{tabular}{|c|c|c|c|}
\hline \multirow{2}{*}{ Gene } & \multicolumn{3}{|c|}{ Grau de identidade de sequência entre espécies } \\
\hline & & A. infulatus & S. sciureus \\
\hline BAX & Homem & 98,0 & 98,5 \\
\hline \multirow[t]{3}{*}{ CCR5 } & S. sciureus & NS & 98,0 \\
\hline & A. trivirgatus & - & 95,5 \\
\hline & Homem & - & 94,0 \\
\hline CCR8 & Homem & 93,1 & 94,1 \\
\hline CD40 & Homem & 91,0 & 91,0 \\
\hline CSF2 & Homem & 91,1 & 89,0 \\
\hline \multirow[t]{6}{*}{ IFN- $\gamma$} & A. lemurinus & 99,0 & 98,0 \\
\hline & A. nancymaae & 97,2 & 96,4 \\
\hline & A. nigriceps & 99,2 & 98,4 \\
\hline & A. vociferans & 99,0 & 98,0 \\
\hline & S. sciureus & 98,4 & 99,2 \\
\hline & Homem & 92,8 & 92,0 \\
\hline \multirow[t]{6}{*}{ IL-2 } & A. lemurinus & 99,0 & 99,4 \\
\hline & A. nancymaae & 99,0 & 99,4 \\
\hline & A. nigriceps & 99,0 & 99,4 \\
\hline & A. vociferans & 99,0 & 99,4 \\
\hline & S. sciureus & 98,4 & 99,0 \\
\hline & Homem & 93,4 & 92,0 \\
\hline \multirow[t]{4}{*}{ IL-3 } & S. sciureus & 94,3 & - \\
\hline & M. mullata & 86,7 & 84,3 \\
\hline & P. troglodytes & 83,6 & 82,0 \\
\hline & Homem & 84,0 & 83,0 \\
\hline \multirow[t]{7}{*}{ IL-4 } & S. sciureus & 92,7 & \\
\hline & M. radiate & 93,5 & 93,5 \\
\hline & P. papio & 88,5 & 88,5 \\
\hline & P. pygmaeus & 90,1 & 90,2 \\
\hline & P. troglodytes & 88,5 & 89,0 \\
\hline & G. gorilla & 89,5 & 90,1 \\
\hline & Homem & 90,1 & 90,2 \\
\hline \multirow[t]{2}{*}{ IL-5 } & S. sciureus & 96,4 & NS \\
\hline & Homem & 95,2 & - \\
\hline \multirow[t]{6}{*}{ IL-10 } & S. sciureus & NS & 97,3 \\
\hline & A. lemurinus & - & 94,4 \\
\hline & A. nancymaae & - & 92,1 \\
\hline & A. nigriceps & - & 94,4 \\
\hline & A. vociferans & - & 94,4 \\
\hline & Homem & - & 89,2 \\
\hline \multirow[t]{5}{*}{ IL-12B } & P. anubis & 90,1 & 90,1 \\
\hline & C. torquatus & 89,3 & 90,1 \\
\hline & M. mullata & 90,1 & 90,1 \\
\hline & P. troglodytes & 88,8 & 91,0 \\
\hline & Homem & 90,6 & 92,3 \\
\hline IL-13 & Homem & 95,7 & 94,3 \\
\hline TGF $\beta 2$ & Homem & 98,0 & 97,4 \\
\hline \multirow[t]{2}{*}{ TNF } & S. sciureus & 95,0 & 99,4 \\
\hline & Homem & 92,4 & 89,2 \\
\hline
\end{tabular}

NS: Não sequenciado. Sinal convencional utilizado: - Dado numérico igual a zero, não resultante de arredondamento. 


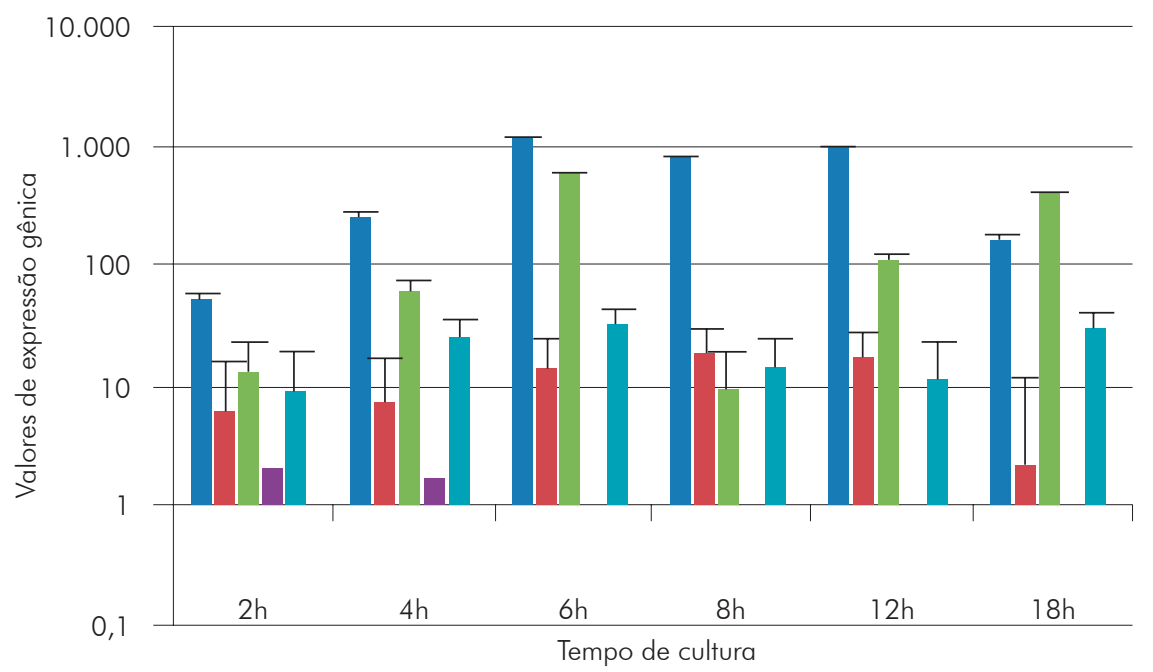

IFN $\gamma$

Os valores no eixo $Y$ representam o aumento relativo da expressão de cada gene em relação ao valor 1 referente ao RNA extraído de PBMCs antes do cultivo celular.

Figura 4 - Cinética de expressão gênica de IFN $\gamma$, IL-10, IL-2, IL-12 e TNF em células mononucleares do sangue periférico (PBMC) de S. sciureus cultivadas por 2, 4, 6, 8,12 e 18 h, sob estimulação dos mitógenos ionomicina/fitohemaglutinina
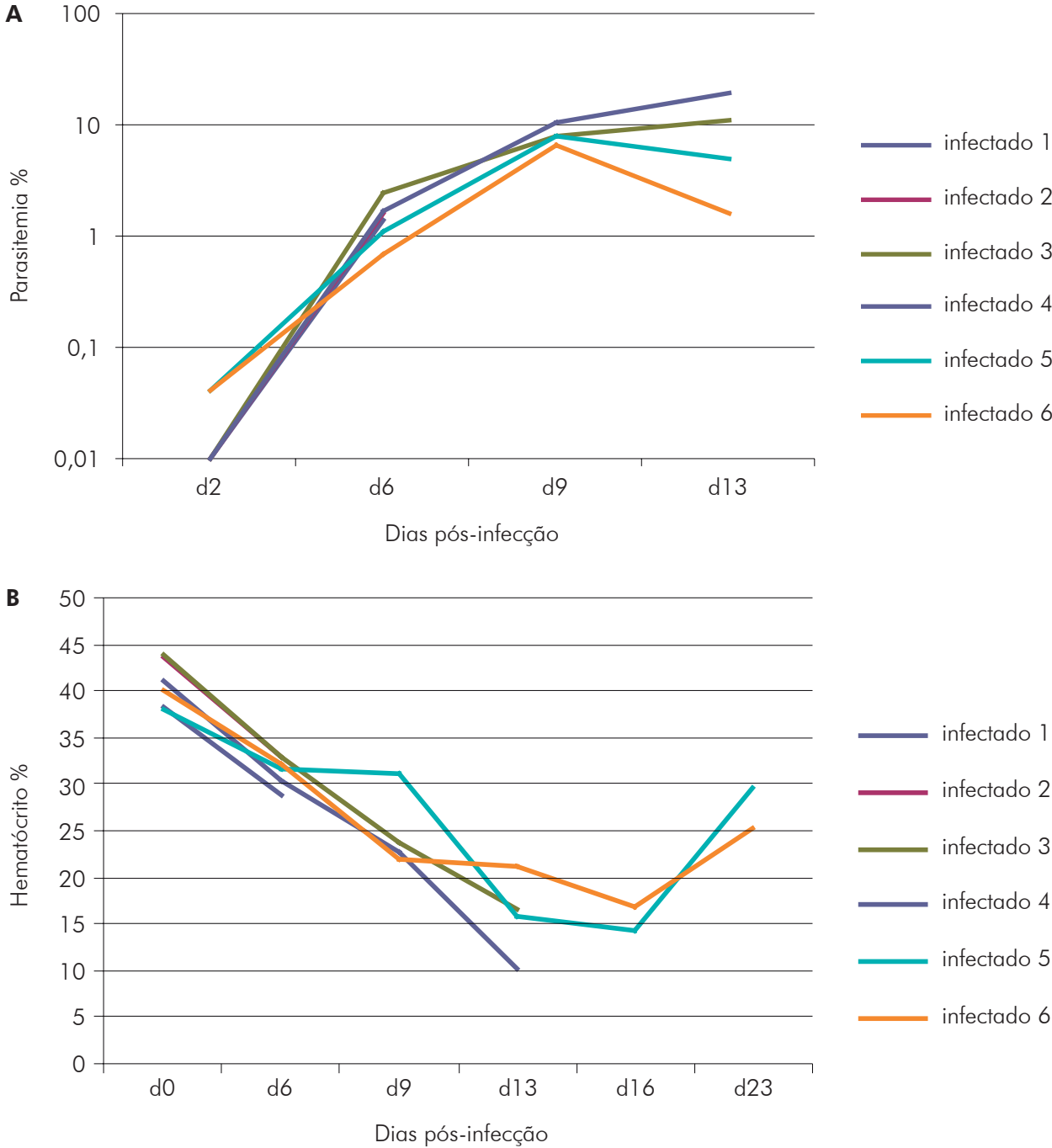

Os animais infectados 1 e 2 foram esplenectomizados com sete dias de infecção, os 3 e 4 foram esplenectomizados com 14 dias de infecção e os infectados 5 e 6 foram esplenectomizados com 28 dias de infecção.

Figura 5 - Cinética de parasitemia (A) e do hematócrito (B) nos S. sciureus nãoesplenectomizados após a infecção com $5 \times 10^{7}$ hemácias parasitadas $/ \mathrm{mL}$ pela cepa FUP de P. falciparum 
cultivadas in vitro sob as seguintes condições: i) em presença de hemácias infectadas por P. falciparum cultivadas in vitro; ii) parasitos livres de P. falciparum; iii) antígenos extraídos de P. falciparum; e iv) hemácias humanas normais. Após $6 \mathrm{~h}$ de cultivo celular, foram realizadas a extração de RNA, a síntese de cDNA e as reações de PCR-TRq para a detecção de IFN $\gamma$, IL-2, IL-6, IL-10, IL-12B, LTA e TNF. Os transcritos de beta actina ( $\beta$-actina) foram usados como controle-interno das reações (controle endógeno).

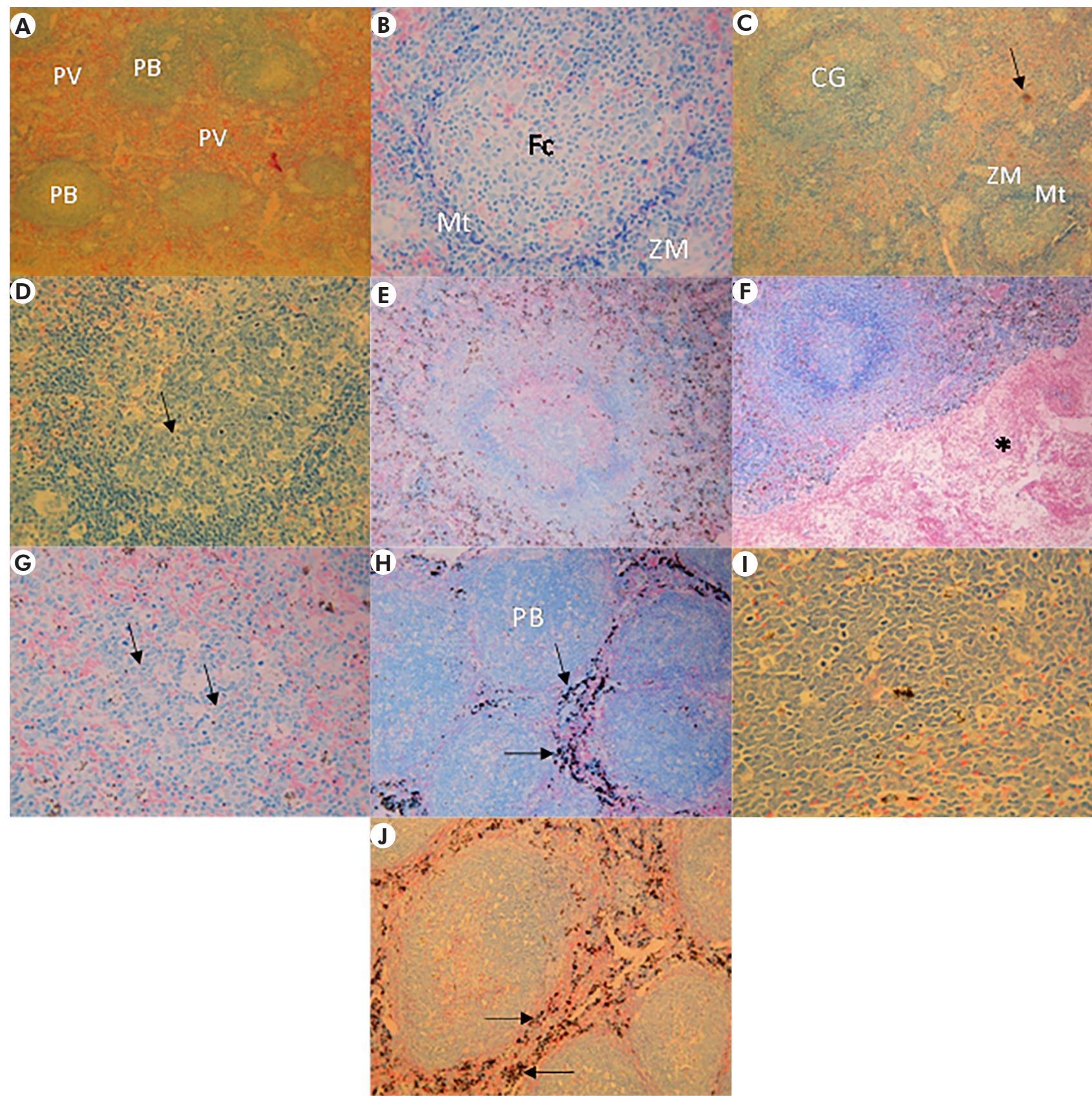

Fotos: Leonardo José de Moura Carvalho. As esplenectomias foram realizadas nos dias sete, 14 ou 28 após a infecção sanguínea. Cortes $(5 \mu \mathrm{m})$ foram realizados, corados com Giemsa e analisados ao microscópio de luz. A: Arquitetura esplênica de animal-controle não-infectado mostrando polpa vermelha (PV) e polpa branca (PB) com aspectos normais. B: Organização da arquitetura da polpa branca do baço de animal-controle não-infectado mostrando folículo de células $B(F c)$, zona do manto $(M t)$ e zona marginal $(Z M)$. C: Baço de animal infectado esplenectomizado sete dias após a infecção sanguínea mostrando centro germinal (CG) aumentado de tamanho delimitado por uma zona do manto escura (Mt) e uma delgada zona marginal (ZM). Na polpa vermelha, pode-se observar deposição de grumos de cor marrom, sugestivos de hemozoína (seta). D: No dia sete, a polpa branca apresentou intensa ativação celular evidenciada por focos de ocorrência de mitoses dentro do centro germinal (setas). E: No dia 14, foi observado aumento do tamanho da polpa branca com evidente perda dos limites com a zona do manto. F: No dia 14, foi observada também uma intensa área de congestão de eritrócitos (asterisco). G: No dia 14, a zona do manto já não era mais evidenciada na polpa branca, ocorreu um aumento de focos de células em divisão celular com presença de muitos centroblastos (setas), e não se pode mais evidenciar um centro germinativo. $\mathbf{H}$ : No dia 28 , a polpa branca (PB) ocupou quase que a totalidade do estroma esplênico e ocorreu intensa deposição de grumos de coloração marrom na polpa vermelha, sugestivos de hemozoína (setas). I: No dia 28 , observou-se um princípio de recuperação da arquitetura normal do baço, mas ainda com uma definição imprecisa entre as zonas da polpa branca. J: No dia 28, observou-se congestão intensa da polpa esplênica vermelha com extensa acumulação de pigmentos sugestivos de hemozoína (setas).

Figura 6 - Análise histopatológica do baço de animais S. sciureus infectados com 5x107 hemácias parasitadas pela cepa FUP de P. falciparum e do baço de animal-controle não-infectado 
A análise de expressão das moléculas em esplenócitos de Saimiri infectados evidenciou uma forte reação inflamatória, mediada principalmente por IFN $\gamma$, com sete dias de infecção, quando já se observava uma desestruturação da arquitetura normal do baço. Com 28 dias, houve uma diminuição da expressão desses genes que coincidiu com uma reestruturação da arquitetura esplênica, que se apresentava ainda com regiões de congestão da microcirculação e importante deposição de hemozoína ${ }^{51}$ (Figura 6). Esses dados corroboram os obtidos em humanos, nos quais demonstrou-se que uma forte reação inflamatória durante os estágios iniciais de infecção é seguida por uma inibição tardia dessa resposta, o que corresponde ao padrão de resposta imune importante para o controle do crescimento do parasito e consequente redução das complicações associadas à imunopatogenia ${ }^{53,54}$.

\section{AVALIAÇÃO DA IMUNOGENICIDADE E DA EFICÁCIA VACINAL DAS PROTEÍNAS MSP-3 E GLURP DE P. FALCIPARUM NOS PRIMATAS NEOTROPICAIS S. SCIUREUS E A. INFULATUS}

A proteína 3 da superfície de merozoíta (MSP-3) e a proteína rica em glutamato (GLURP) são candidatas a entrar na composição de uma vacina antimalárica, com base em dados experimentais e epidemiológicos sólidos. Essas proteínas são capazes de induzir altos títulos de anticorpos específicos, que estão correlacionados com diversos graus de proteção clínica de indivíduos residentes em áreas endêmicas, proteção contra alta parasitemia e contra a doença. Tais correlações, assim como a capacidade de anticorpos isolados de indivíduos imunes inibirem o crescimento do parasito in vitro, também foram observadas na Amazônia brasileira ${ }^{55}$.
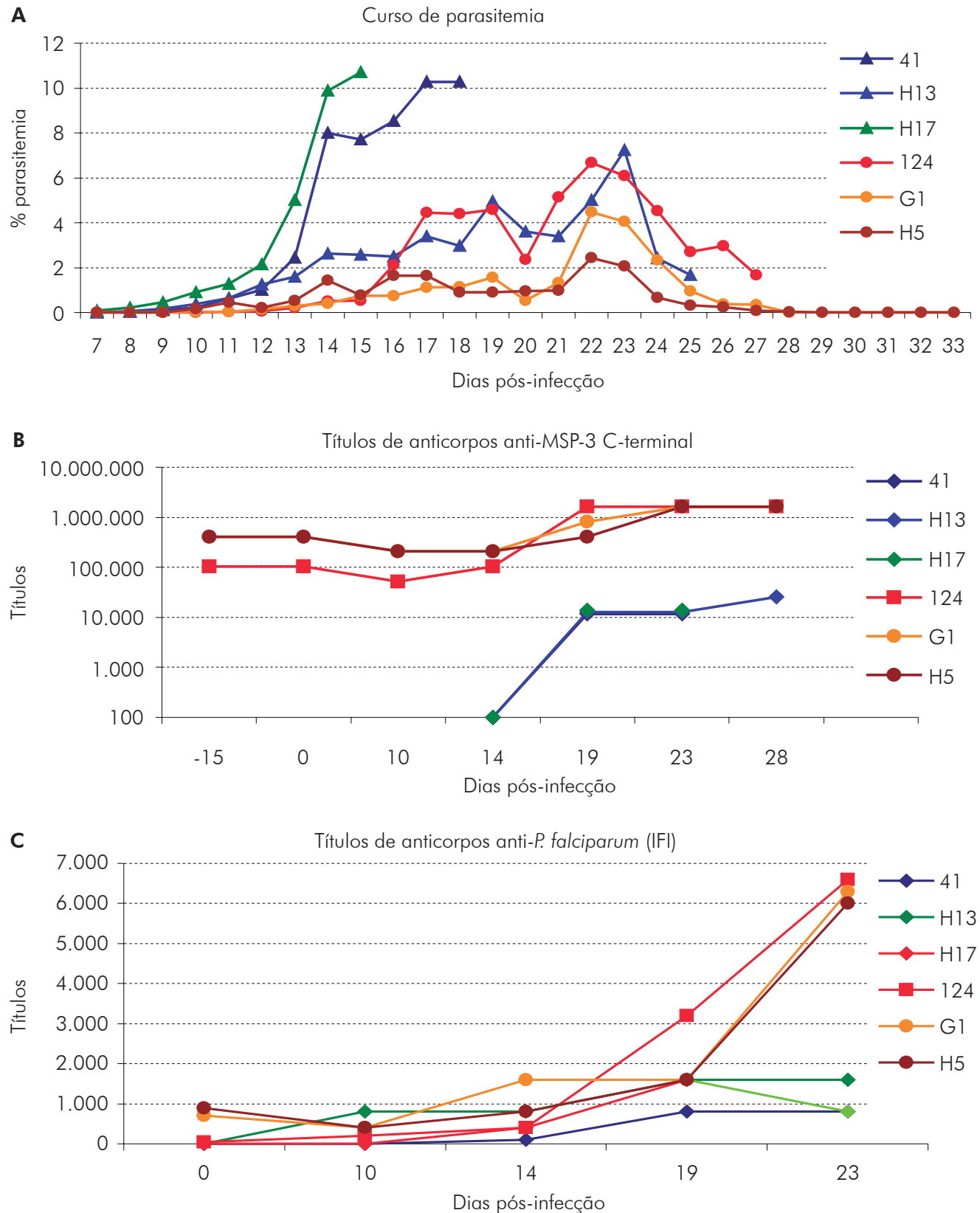

Figura 7 - Curso de parasitemia (A) e títulos de anticorpos anti-MSP-3 C-terminal (ELISA) (B) e anti-parasito (IFI) (C) em macacos S. sciureus, imunizados com MSP-3 C-terminal (Saimiri 124, G1 e H5) ou controles não imunizados (Saimiri 41, H13 e H17), inoculados com 50.000 hemácias parasitadas por P. falciparum 
Diante disso, o LabMal se propôs a avaliar a imunogenicidade e a capacidade de indução de imunidade protetora desses antígenos utilizando primatas neotropicais $S$. sciureus e A. infulatus. A avaliação consistiu em verificar se os antígenos-teste, em associação com diferentes adjuvantes, eram imunogênicos e capazes de induzir proteção, e estudar o grau de semelhança entre a resposta imune gerada e aquela observada no homem, no que se refere ao reconhecimento dos antígenos e aos mecanismos de proteção envolvidos 56,57 .

Quatro construções derivadas de MSP-3 e uma de GLURP foram avaliadas. As construções derivadas da MSP-3 foram as proteínas recombinantes DG210 e MSP-3 C-terminal e os peptídeos sintéticos MSP-3b e MSP-3 TLP (très long peptide - peptídeo muito longo), em combinação com cinco adjuvantes diferentes (ribi, IFA, SBAS2, Montanide ISA 720 e PMC), além de uma construção MSP-3 MAP (multiple antigen peptide antígeno multipeptídico). Com relação à GLURP, uma única combinação consistiu na proteína recombinante RO associada ao adjuvante hidróxido de alumínio (alum).

Os dados mostraram que a imunogenicidade da MSP-3 dependeu tanto da proteína ou do peptídeo utilizado quanto do adjuvante. As formulações MSP-3b-IFA, DG210-IFA, MSP-3 C-terminal-SBAS2 e
MSP-3 C-terminal-Montanide ISA 720 foram testadas em S. sciureus e se mostraram imunogênicas; as formulações MSP-3 TLP-SBAS2 e MSP-3 TLP-PMC foram testadas em $S$. sciureus e $A$. infulatus e se mostraram imunogênicas para ambas as espécies. Entretanto, a formulação MSP-3 C-terminal-SBAS2 foi a mais eficaz em induzir imunidade protetora contra o desafio por P. falciparum em S. sciureus, existindo uma correlação entre a resposta imune dos animais imunizados e a proteção contra a infecção, visto que os soros dos animais protegidos apresentaram títulos mais altos de anticorpos contra o parasito do que os não protegidos (Figura 7).

A formulação RO-alum foi testada em S. sciureus e A. infulatus e se mostrou imunogênica em ambas as espécies, sendo capaz de induzir imunidade protetora contra o desafio em um Saimiri que apresentou título elevado de anticorpos contra o parasito ${ }^{52}$. A proteção foi correlacionada com a resposta imune apresentada por esse Saimiri em comparação com os Saimiri não protegidos. Esse animal protegido apresentou baixas parasitemias e altos títulos de anticorpos contra RO e contra o parasito (Figura 8). Além disso, a proteção estava relacionada com o amplo reconhecimento da proteína nativa e com o amplo perfil de reconhecimento epitópico da proteína imunizante.

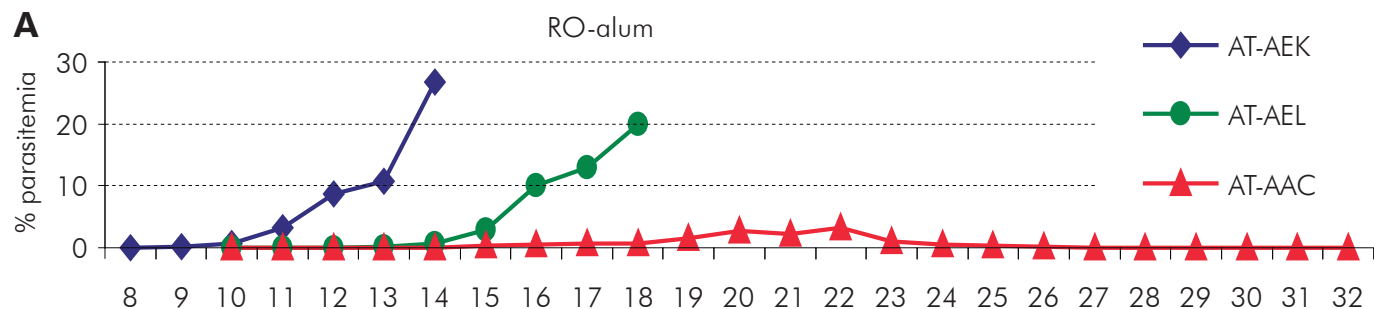

Dias pós-infecção

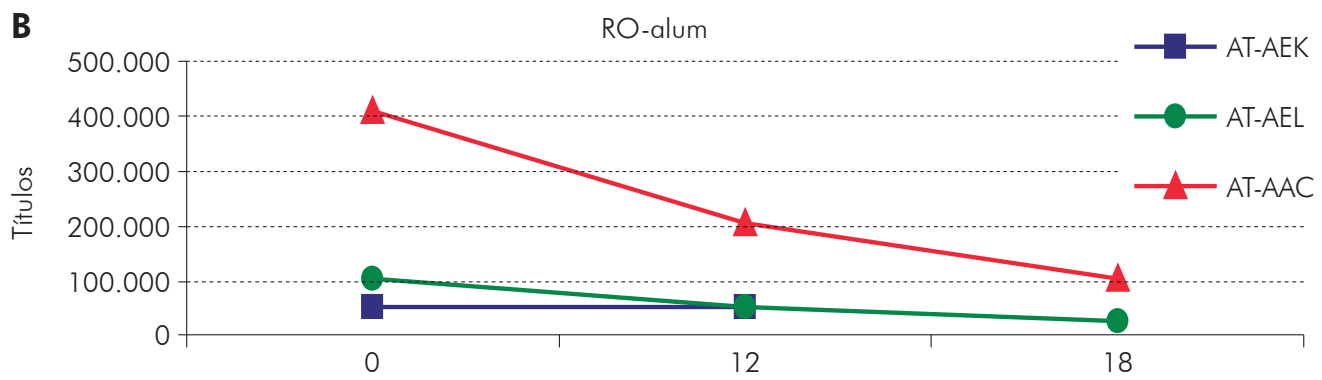

Dias pós-infecção

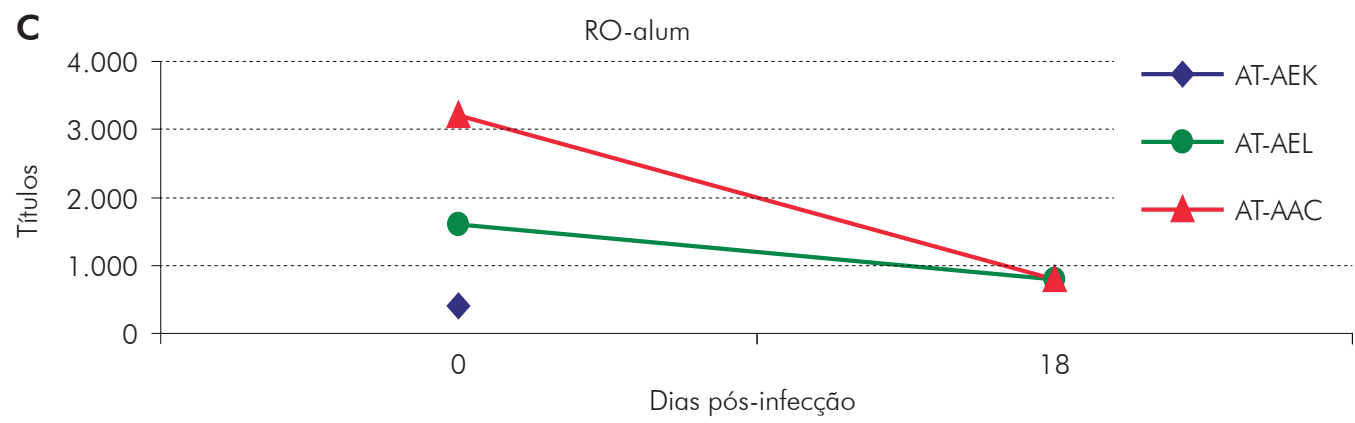

Figura 8 - Curso de parasitemia $(\mathbf{A})$ e títulos de anticorpos anti-RO (B) e anti-parasito (C) em S. sciureus protegido (AT-AAC) e não-protegidos (AT-AEK e AT-AEL) imunizados com RO-alum e inoculados com 5.000 hemácias parasitadas por $P$. falciparum 
Foram realizados experimentos de inibição celular dependente de anticorpo (ADCI), com soros de animais imunizados, soros imunes (pools e soros individuais), imunoglobulinas (lg) purificadas a partir de um pool de soros imunes (PIS) e de um pool de soros normais (SNS), e anticorpos anti-MSP-3b e anti-RO purificados a partir da lg imune ${ }^{53}$. Os dados mostraram que soros e anticorpos anti-MSP-3 purificados de Saimiri imunes possuem um forte poder inibidor do crescimento do parasito, sendo capazes de eliminá-lo na presença ou não de monócitos. Entre os animais imunizados, não houve correlação entre proteção e capacidade de inibição do crescimento do parasito in vitro (Figura 9). Em conjunto, esses dados mostraram que o mecanismo de ação inibitória do crescimento in vitro de P. falciparum dos anticorpos anti-MSP-3 e anti-RO de $S$. sciureus pode não envolver necessariamente cooperação com monócitos, ao contrário do mecanismo de $A D C l$ descrito na resposta imune em humanos imunes ${ }^{54,55}$. Não está excluído, entretanto, que tal mecanismo também opere no modelo simiano.

Considerando que, de todas as formulações testadas, as que se apresentaram mais imunogênicas e capazes de induzir proteção parcial em Saimiri foram a proteína recombinante MSP-3 C-terminal em associação com o adjuvante $\mathrm{ASO2}$ e a região RO da GLURP em associação com o alume, o LabMal avaliou a imunogenicidade e a eficácia de uma proteína recombinante híbrida GLURP/MSP-3 ${ }^{52}$. Essa proteína híbrida, que contém as regiões C-terminal da MSP-3 e RO da GLURP, foi expressa em Lactococcus lactis e formulada com três diferentes adjuvantes, alum, Montanide ISA 720 e Freund.

A

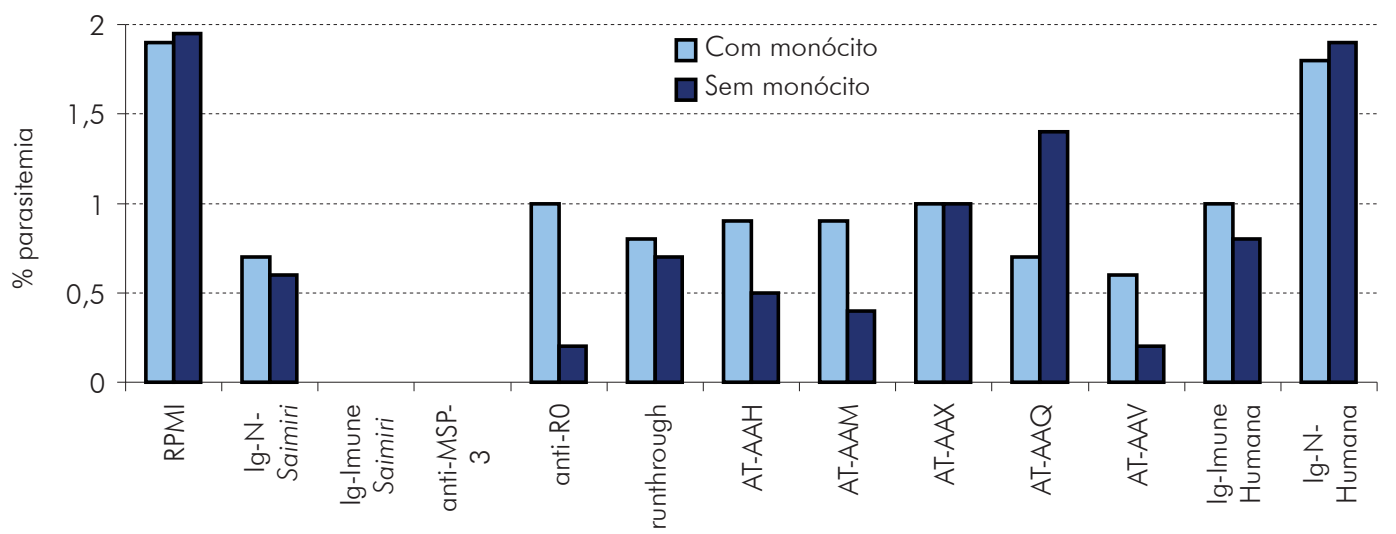

Amostras

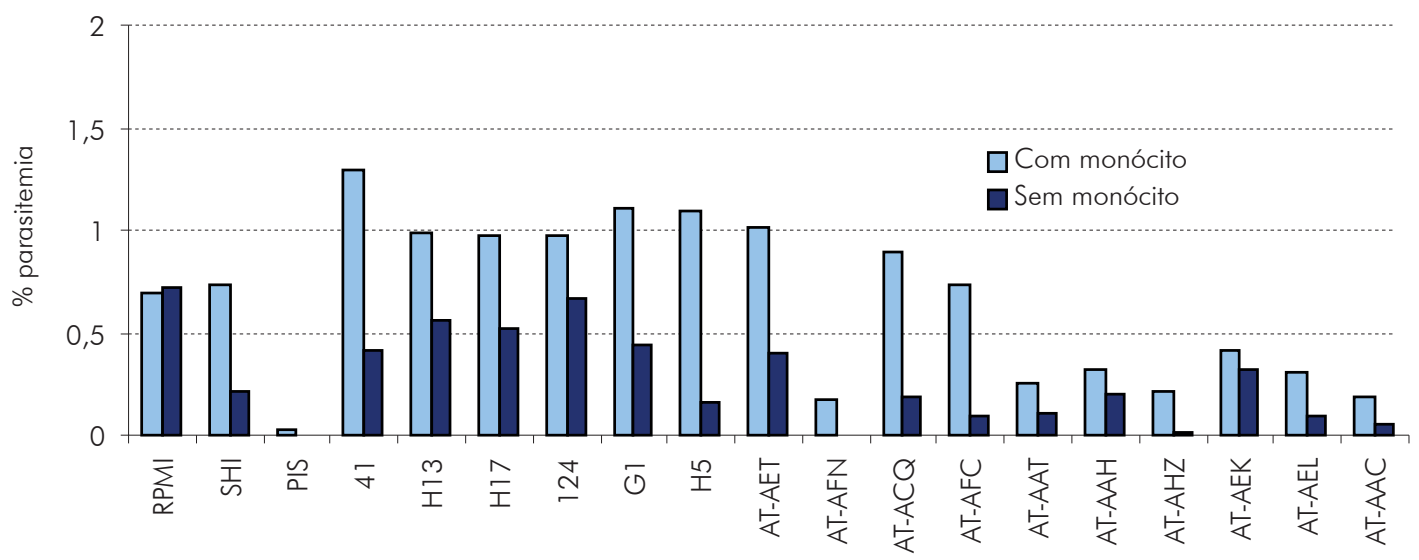

Amostras

A: AT-AAH: S. sciureus imunizado com RO-alum (pré-desafio); AT-AAM até AT-AAV: S. sciureus imunizados com DG210IFA (pré-desafio); B: PIS e SHI: soros imunes de S. sciureus; 41, H13 e H17: soros de S. sciureus não imunizados; 124 , G1, H5, AT-AET e AT-AFN: soros de S. sciureus imunizados com MSP-3 C-terminal-SBAS2 (pré-desafio); AT-ACQ e ATAFC: soros de S. sciureus imunizados com DG210-IFA (pré-desafio); AT-AAT, AT-AAH, AT-AHZ, AT-AEK, AT-AEL e AT-AAC: soros de S. sciureus imunizados com RO-alum.

Figura 9 - Efeito de soros ou imunoglobulinas de macacos S. sciureus tornados imunes por repetidas infecções por P. falciparum ou imunizados com MSP-3 ou GLURP sobre o crescimento in vitro de P. falciparum, na presença de monócitos (ensaio de $\mathrm{ADCl}$ ) ou não 
Vinte macacos Saimiri foram imunizados com as diferentes formulações e desafiados com 50.000 Pfhp. Os dados mostraram que as três formulações testadas foram imunogênicas e que, na maioria dos casos, duas doses eram suficientes para elicitar altos níveis de anticorpos. A formulação GLURP/MSP-3-Freund induziu títulos mais altos de anticorpos, enquanto a formulação GLURP/MSP-3-alum induziu os títulos mais baixos de anticorpos. Com a formulação GLURP/MSP-3-Montanide ISA 720, os títulos de anticorpos variaram (Figura 10), com dois animais apresentando altos títulos de anticorpos e três apresentando baixos títulos de anticorpos. Títulos de anticorpos foram maiores para a proteína GLURP que para MSP-3 (Figura 11), e, de uma maneira geral, os títulos de anticorpos para as proteínas individuais foram mais baixos do que os títulos de anticorpos para a proteína híbrida GLURP/MSP-3.
Após o desafio, os cinco Saimiri imunizados com GLURP/MSP-3-alume apresentaram um rápido aumento na parasitemia. Os dois Saimiri imunizados com GLURP/MSP-3-Montanide ISA 720 que apresentaram altos títulos de anticorpos tiveram um retardo no aparecimento da parasitemia. No grupo de animais imunizados com GLURP/MSP-3-Freund, a parasitemia permaneceu baixa em um dos cinco animais e outros três desenvolveram uma parasitemia relativamente alta, mas foram capazes de mantê-la abaixo de 10\% por vários dias (Figura 12). Quando os animais foram reagrupados de acordo com o resultado obtido nos experimentos de desafio (nenhuma proteção versus proteção parcial ou proteção total), foi observada uma associação estatisticamente significativa entre altos títulos de anticorpos e proteção. Em conjunto, os dados mostraram que GLURP e MSP-3 são capazes de induzir proteção contra a infecção ${ }^{45,52,53}$.

\section{GLURP/MSP-3 - alume}

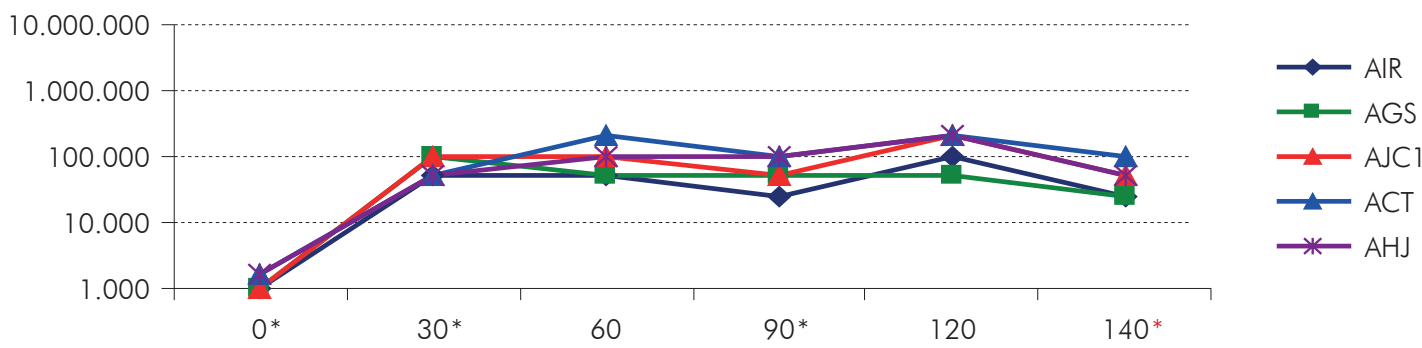

GLURP/MSP-3 - Montanide ISA720

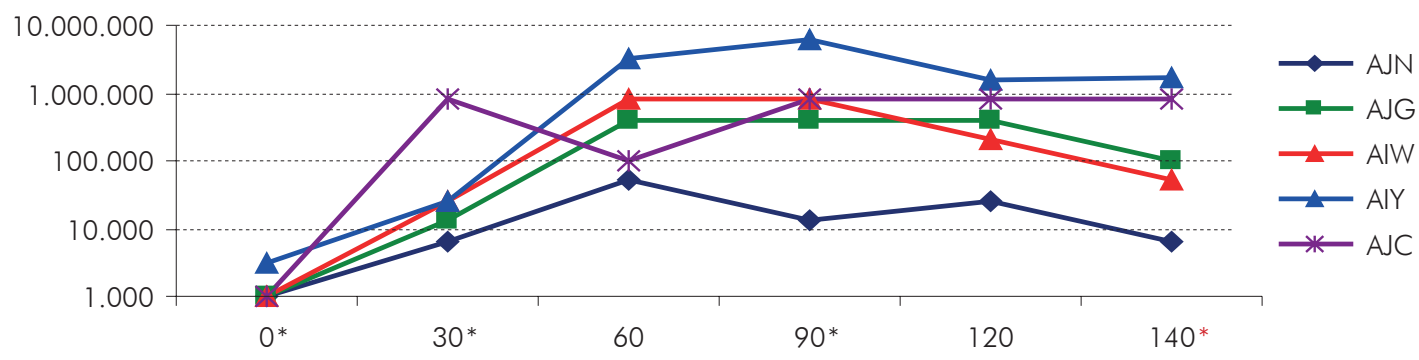

GLURP/MSP-3 - Freund

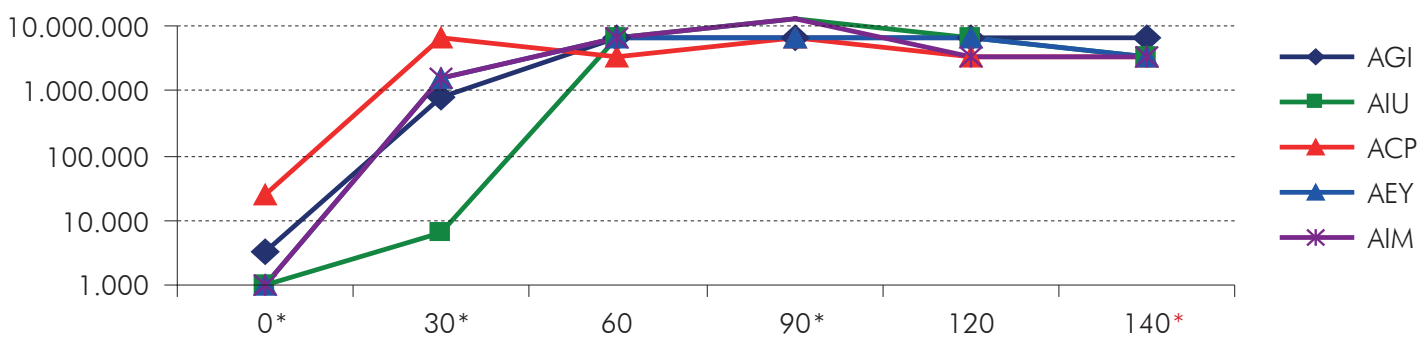

* Imunizações; * Desafio.

Figura 10 - Evolução dos títulos de anticorpos anti-GLURP/MSP-3 híbrida (em ELISA) em S. sciureus imunizados com a proteína híbrida 
GLURP/MSP-3 - alume

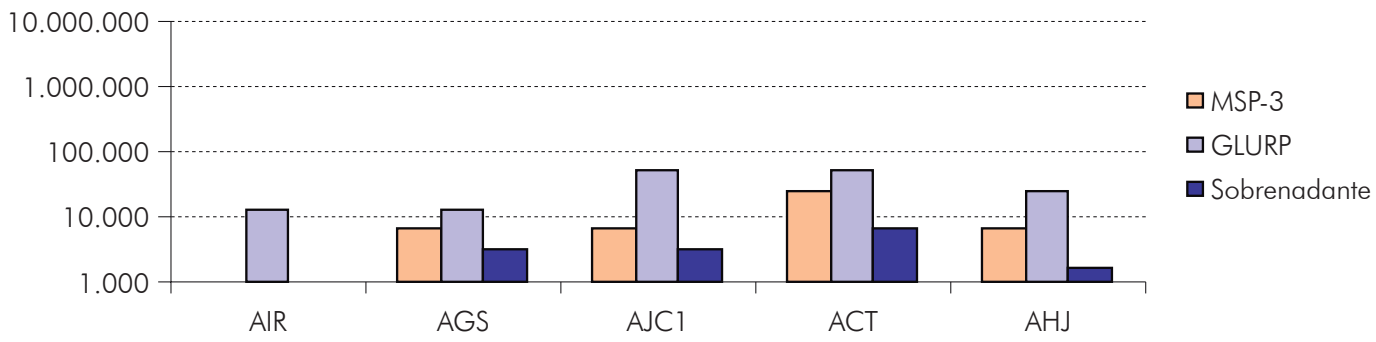

GLURP/MSP-3 - Montanide ISA720

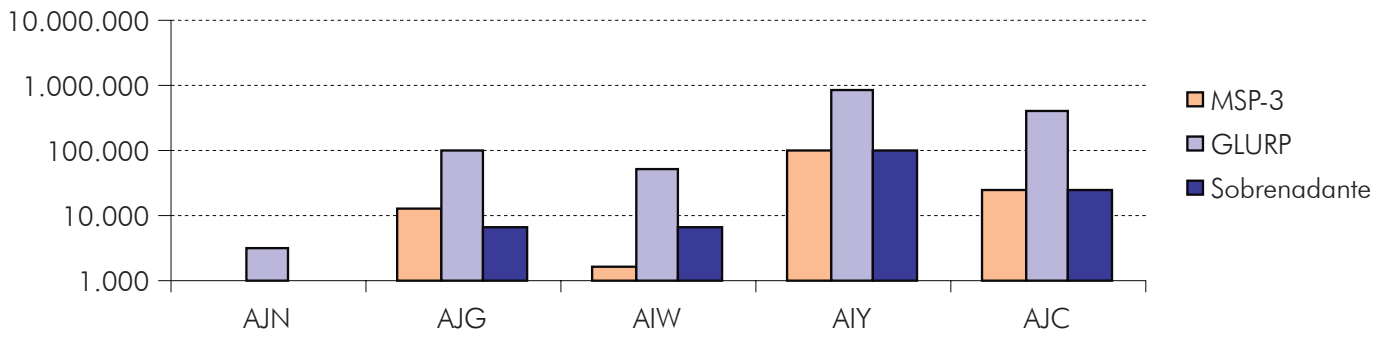

GLURP/MSP-3 - Freund

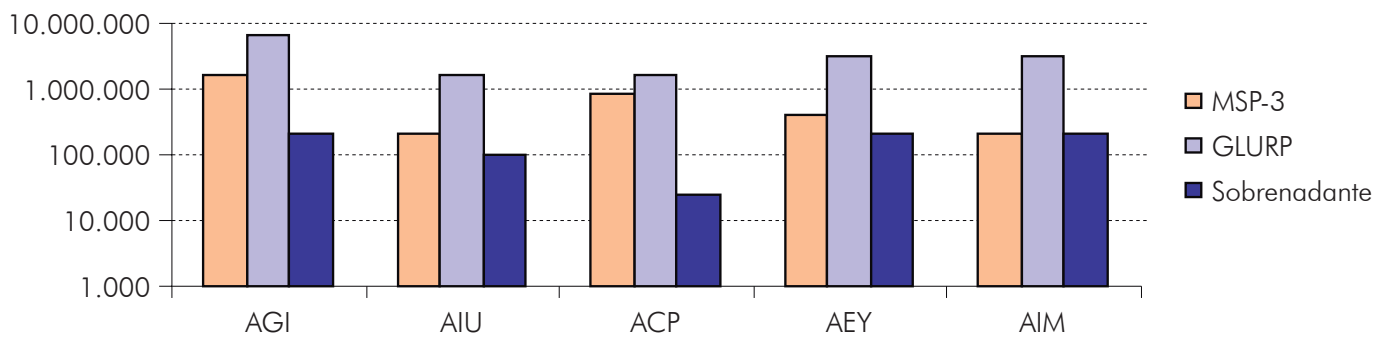

Figura 11 - Títulos de anticorpos anti-MSP-3 C-terminal, anti-GLURP/RO e anti-sobrenadante de cultura de Lactococcus (controle) em S. sciureus imunizados com a proteína híbrida GLURP/MSP-3

\section{CONCLUSÃO}

Em suma, os dados relacionados no presente trabalho, frutos da parceria entre o LabMal e o CENP, mostraram que os primatas neotropicais $A$. infulatus, esplenectomizados ou não, são susceptíveis à infecção experimental por $P$. falciparum, representando um modelo experimental indicado para ensaios vacinais de antígenos plasmodiais. Adicionalmente, os $A$. infulatus são susceptíveis ao desenvolvimento de anemia grave, tornando-os bons modelos de estudos experimentais em malária humana, também no que diz respeito à patogênese de anemia grave.

Apesar de, inicialmente, as sequências humanas servirem como molde para o desenho de iniciadores empregados na amplificação e sequenciamento de genes de macacos Saimiri e Aotus, as diferenças genômicas existentes entre humanos, Saimiri e Aotus são suficientes para coibir ou inibir o uso de iniciadores baseados em sequências humanas, sendo, portanto, necessário o desenvolvimento de ferramentas específicas para primatas neotropicais. $O$ desenvolvimento de uma PCR em tempo real, utilizando iniciadores específicos para primatas neotropicais, permitiu a análise de várias citocinas alteradas durante a infecção por malária, e essa técnica é considerada a melhor ferramenta para avaliação da resposta imune celular em S. sciureus.
A imunização de primatas Saimiri e Aotus com quatro construções derivadas da proteína MSP-3 e uma da proteína GLURP com diferentes adjuvantes (Ribi, IFA, SBAS2, Montanide ISA 720 e PMC) mostrou que as formulações MSP-3 C-terminal-SBAS2 e RO-alum foram imunogênicas e capazes de induzir imunidade protetora contra o desafio por P. falciparum. A imunização induziu a produção de anticorpos capazes não apenas de inibir o crescimento, mas de eliminar os parasitos, na presença ou não de monócitos.

Finalmente, a imunização de macacos Saimiri com uma proteína recombinante híbrida contendo as regiões C-terminal da MSP-3 e RO da GLURP expressa em Lactococcus lactis e formulada com três diferentes adjuvantes (alum, Montanide ISA 720 e Freund) mostrou que as três formulações são imunogênicas e capazes de induzir a formação de anticorpos protetores.

Em conjunto, os dados obtidos no LabMal, em uma colaboração de cerca de 25 anos com o CENP/IEC, mostram que os antígenos GLURP e MSP-3 são capazes de induzir proteção contra a infecção plasmodial e que os modelos $A$. infulatus/P. falciparum e S. sciureus/P. falciparum são boas alternativas para ensaios vacinais de antígenos plasmodiais. 
GLURP/MSP-3 - alume

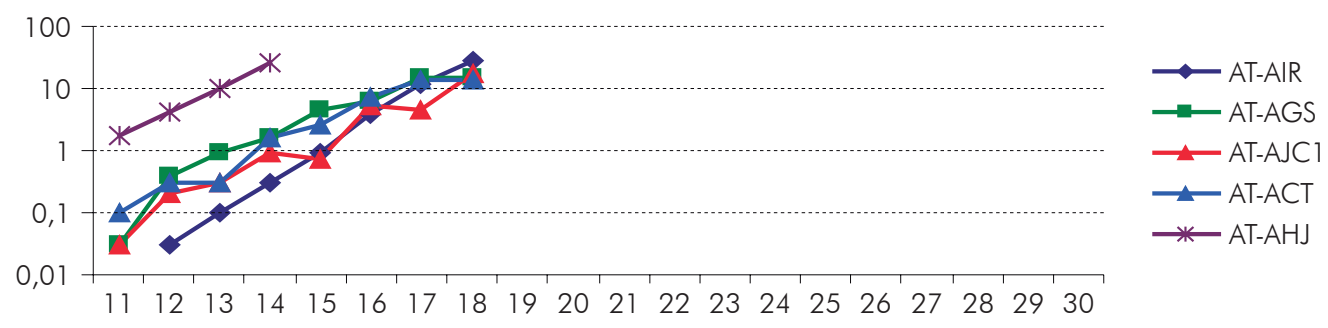

GLURP/MSP-3 - Montanide ISA720

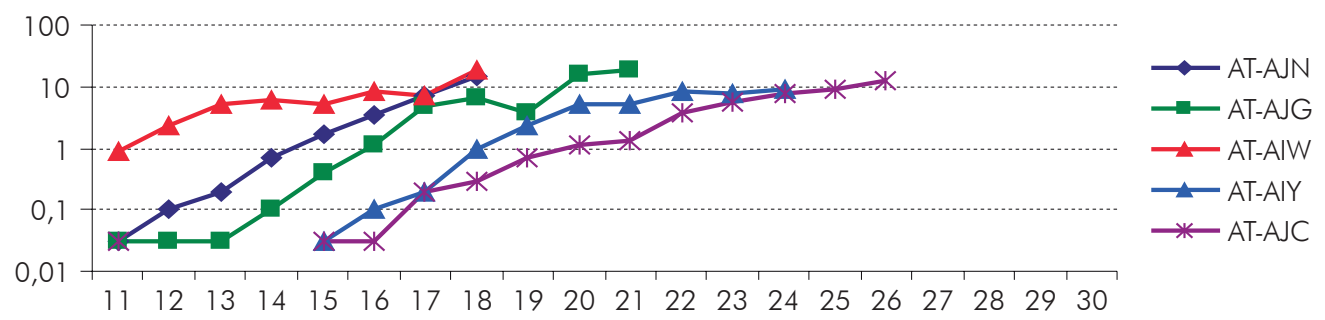

GLURP/MSP-3 - Freund

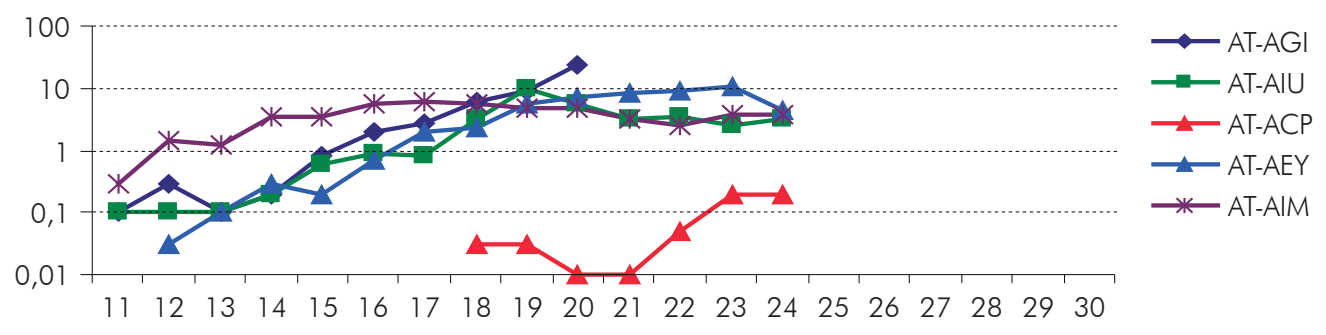

Figura 12 - Curso de parasitemia em S. sciureus imunizados com GLURP/MSP-3 híbrida e com sobrenadante de cultura de Lactococcus (controle) e inoculados com 50.000 hemácias parasitadas por P. falciparum

Entretanto, apesar de serem os melhores modelos para a avaliação de vacinas antimaláricas, existem pontos a serem melhorados na sua utilização.

\section{CONFLITOS DE INTERESSE}

Os autores declaram que não há conflitos de interesse.

\section{CONTRIBUIÇÃO DOS AUTORES}

Todos os autores contribuíram com a idealização do estudo, a análise e a interpretação dos dados e com a redação do manuscrito, aprovando a versão final publicada. Declaram-se responsáveis pelo conteúdo integral do artigo, garantindo sua precisão e integridade.

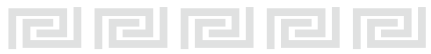

\section{REFERÊNCIAS}

1 Menkin-Smith L, Winders WT. Plasmodium vivax malaria. Treasure Island (FL): StatPearls Publishing; 2020 Aug 11.

2 World Health Organization. World malaria report 2019 [Internet]. Geneva: World Health Organization; 2019 [cited 2021 May 20]. Available from: https://www.who.int/malaria/publications/ world_malaria_report/en/.

3 Rajahram GS, Cooper DJ, WilliamT, Grigg MJ, Anstey NM, Barber BE. Deaths from Plasmodium knowlesi malaria: case series and systematic review. Clin Infect Dis. 2019 Oct;69(10):1703-11.
4 Rajahram GS, Barber BE, William T, Grigg MJ, Menon J, Yeo TW, et al. Falling Plasmodium knowlesi malaria death rate among adults despite rising incidence, Sabah, Malaysia, 2010-2014. Emerg Infect Dis. 2016 Jan;22(1):41-8.

5 Rajahram GS, Barber BE, Yeo TW, Tan WW, William T. Case report: fatal Plasmodium knowlesi malaria following an atypical clinical presentation and delayed diagnosis. Med J Malaysia. 2013;68(1):71-2.

6 Cox-Singh J, Hiu J, Lucas SB, Divis PC, Zulkarnaen $M$, Chandran $P$, et al. Severe malaria - a case of fatal Plasmodium knowlesi infection with post-mortem findings: a case report. Malar J. 2010 Jan;9:10. 
7 Brasil P, Zalis MG, Pina-Costa A, Siqueira AM, Bianco Jr C, Silva $S$, et al. Outbreak of human malaria caused by Plasmodium simium in the Atlantic Forest in Rio de Janeiro: a molecular epidemiological investigation. Lancet Glob Health. 2017 Oct;5(10):e1038-e1046.

8 Chrubasik C, Jacobson RL. The development of artemisinin resistance in malaria: reasons and solutions. Phytother Res. 2010 Jul;24(7): 1104-6.

9 Saralamba S, Pan-Ngum W, Maude RJ, Lee SJ, Tarning J, Lindegardh $\mathrm{N}$, et al. Intrahost modeling of artemisinin resistance in Plasmodium falciparum. Proc Natl Acad Sci USA. 2011 Jan; 108(1):397-402.

10 Pribluda VS, Evans L 3rd, Barillas E, Marmion J, Lukulay P, Chang J. Were medicine quality and pharmaceutical management contributing factors in diminishing artemisinin efficacy in Guyana and Suriname? Malar J. 2014 Mar; 13:77.

11 World Health Organization. World malaria report 2014 [Internet]. Geneva: World Health Organization; 2014 [cited 2021 May 20]. Available from: https://www.who.int/malaria/publications/wor Id_malaria_report_2014/en/.

12 Ricotta E, Kwan J. Artemisinin-resistant malaria as a global catastrophic biological threat. Curr Top Microbiol Immunol. 2019;424:33-57.

13 Müller O, Lu G, Jahn A, Mockenhaupt FP. How worthwhile is methylene blue as a treatment of malaria? Expert Rev Anti Infect Ther. 2019 Jul;17(7):471-3.

14 World Health Organization. Global technical strategy for malaria 2016-2030 [Internet]. Geneva: World Health Organization; 2015 [cited 2021 May 20]. Available from: https:// apps.who.int/iris/bitstream/handle/10665/ $176712 / 9789241564991$ eng.pdf;isessionid= C7A3A7005E 18 CF $1470 \overline{6} 9$ B6DFBAB77B4E? sequence $=1$.

15 Rowe JA, Claessens A, Corrigan RA, Arman M. Adhesion of Plasmodium falciparum-infected erythrocytes to human cells: molecular mechanisms and therapeutic implications. Expert Rev Mol Med. 2009 May 26;1 1:e16.

16 Quintero JP, Siqueira AM, Tobón A, Blair S, Moreno A, Arévalo-Herrera $M$, et al. Malaria-related anaemia: a Latin American perspective. Mem Inst Oswaldo Cruz. 2011 Aug;106 Suppl 1(Suppl 1):91-104.

17 Carvalho LJM, Daniel-Ribeiro CT, Goto H. Malaria vaccine: candidate antigens, mechanisms, constraints and prospects. Scand J Immunol. 2002 Oct;56(4):327-43.
18 Reed ZH, Friede M, Kieny MP. Malaria vaccine development: progress and challenges. Curr Mol Med. 2006 Mar;6(2):231-45.

19 Vaughan AM, Kappe SH. Malaria vaccine development: persistent challenges. Curr Opin Immunol. 2012 Jun;24(3):324-31.

20 Schwartz L, Brown GV, Genton B, Moorthy VS. A review of malaria vaccine clinical projects based on the WHO rainbow table. Malar J. 2012 Jan; 1 1:11.

21 Keating C. The history of the RTS,S/ ASO1 malaria vaccine trial. Lancet. 2020 Apr;395(10233):1336-7.

22 Laurens MB. RTS,S/ASO1 vaccine (Mosquirix ${ }^{T M}$ ): an overview. Hum Vaccin Immunother. 2020 Mar; 16(3):480-9.

23 Gordon DM, McGovern TW, Krzych U, Cohen JC, Schneider I, LaChance R, et al. Safety, immunogenicity, and efficacy of a recombinantly produced Plasmodium falciparum circumsporozoite protein-hepatitis B surface antigen subunit vaccine. J Infect Dis. 1995 Jun;171(6):1576-85.

24 Bejon P, Lusingu J, Olotu A, Leach A, Lievens $M$, Vekemans J, et al. Efficacy of RTS,S/AS01E vaccine against malaria in children 5 to 17 months of age. N Engl J Med. 2008 Dec;359(24):2521-32.

25 Abdulla S, Oberholzer R, Juma O, Kubhoja S, Machera F, Membi C, et al. Safety and immunogenicity of RTS,S/ASO2D malaria vaccine in infants. N Engl J Med. 2008 Dec;359(24):2533-44.

26 Agnandii ST, Lell B, Soulanoudjingar SS, Fernandes JF, Abossolo BP, Conzelmann C, et al. First results of phase 3 trial of RTS,S/ASO1 malaria vaccine in African children. N Engl J Med. 2011 Nov;365(20): 1863-75.

27 Agnandii ST, Lell B, Fernandes JF, Abossolo BP, Methogo BGNO, Kabwende $A L$, et al. A phase 3 trial of RTS,S/ASO1 malaria vaccine in African infants. N Engl J Med. 2012 Dec;367(24):2284-95.

28 The RTS,S Clinical Trials Partnership. Efficacy and safety of the RTS,S/ASO 1 malaria vaccine during 18 months after vaccination: a phase 3 randomized, controlled trial in children and young infants at 11 African sites. PLoS Med. 2014 Jul; 11 (7):e 1001685.

29 White MT, Verity R, Griffin JT, Asante KP, Owusu-Agyei S, Greenwood B, et al. Immunogenicity of the RTS,S/ASO1 malaria vaccine and implications for duration of vaccine efficacy: secondary analysis of data from a phase 3 randomised controlled trial. Lancet Infect Dis. 2015 Dec;15(12): 1450-8.

30 Craig AG, Grau GE, Janse C, Kazura JW, Milner D, Barnwell JW, et al. The role of animal models for research on severe malaria. PLoS Pathog. 2012 Feb;8(2):e1002401. 
31 Beignon AS, Le Grand R, Chapon C. In vivo imaging in NHP models of malaria: challenges, progress and outlooks. Parasitol Int. 2014 Feb;63(1):206-15.

32 Lombardini ED, Gettayacamin M, Turner $\mathrm{GDH}$, Brown AE. A review of Plasmodium coatneyi-Macaque models of severe malaria. Vet Pathol. 2015 Nov;52(6):998-1011.

33 Martinelli A, Culleton R. Non-human primate malaria parasites: out of the forest and into the laboratory. Parasitology. 2018 Jan; 145(1):41-54.

34 Riccio EKP, Pratt-Riccio LR, Bianco-Jr C, Sanchez V, Totino PRR, Carvalho LJM, et al. Molecular and immunological tools for the evaluation of the cellular immune response in the neotropical monkey Saimiri sciureus, a non-human primate model for malaria research. Malar J. 2015 Apr;1 4:166.

35 Kennedy RC, Shearer MH, Hildebrand W. Nonhuman primate models to evaluate vaccine safety and immunogenicity. Vaccine. 1997 Jun; 15(8):903-8.

36 World Health Organization. Role of non-human primates in malaria vaccine development: memorandum from a $\mathrm{WHO}$ meeting. Bull WHO. 1988;66(6):719-28.

37 Reynolds J. Report on the Biomedical Primate Research Centre. Annual resource guide 1999-2000. Primate supply information clearinghouse. Washington: Regional Primate Research Center; 2001.

38 Bailey J. Non-human primates in medical research and drug development: a critical review. Biog Amines. 2005;19(4):235-55.

39 Collins WE. South American monkeys in the development and testing of malarial vaccines - a review. Mem Inst Oswaldo Cruz. 1992;87 Suppl $3: 401-6$

40 Criswell BS, Butler WT, Rossen RD, Knight V. Murine malaria: the role of humoral factors and macrophages in destruction of parasitized erythrocytes. J. Immunol. 1971 Jul;107(1):212-21.

41 Achtman AH, Khan M, MacLennan ICM, Langhorne J. Plasmodium chabaudi chabaudi infection in mice induces strong B cell responses and striking but temporary changes in splenic cell distribution. J Immunol. $2003 \mathrm{Jul} ; 171(1): 317-24$.

42 Leisewitz AL, Rockett KA, Gumede B, Jones M, Urban B, Kwiatkowski DP. Response of the splenic dendritic cell population to malaria infection. Infect Immun. 2004 Jul;72(7):4233-9.

43 Hershkovitz P. Two new species of night monkeys, genus Aotus (Cebidae, platyrrhini): a preliminary report on Aotus taxonomy. Am J Primatol. $1983 ; 4(3): 209-43$.
44 Collins WE, Galland GG, Sullivan JS Morris $\mathrm{CL}$, Richardson BB. The Santa Lucia strain of Plasmodium falciparum as a model for vaccine studies. II. Development of Aotus vociferans as a model for testing transmission-blocking vaccines. Am J Trop Med Hyg. 1996 Apr;54(4): 380-5.

45 Carvalho LJM, Oliveira SG, Alves FA, Brígido MCO, Muniz JAPC, Daniel-Ribeiro CT. Aotus infulatus monkey is susceptible to Plasmodium falciparum infection and may constitute an alternative experimental model for malaria. Mem Inst Oswaldo Cruz. 2000 May-Jun;95(3):363-5.

46 Carvalho LJM, Alves FA, Oliveira SG, Rio do Valle RD, Fernandes AAM, Muniz JAPC, et al. Severe anemia affects both splenectomized and non-splenectomized Plasmodium falciparum-infected Aotus infulatus monkeys. Mem Inst Oswaldo Cruz. 2003 Jul;98(5):679-86.

47 Kakoma I, James MA, Whiteley HE, Montelegre F, Buese M, Fafjar-Whestone CJ, et al. Platelet kinetics and other hematological profiles in experimental Plasmodium falciparum infection: a comparative study between Saimiri and Aotus monkeys. Korean J Parasitol. 1992 Sep;30(3):177-82.

48 Jones TR, Stroncek DF, Gozalo AS, Obaldia 3rd N, Andersen EM, Lucas C, et al. Anemia in parasite- and recombinant protein-immunized Aotus monkeys infected with Plasmodium falciparum. Am J Trop Med Hyg. 2002 Jun;66(6):672-9.

49 Egan AF, Fabucci ME, Saul A, Kaslow DC, Miller LH. Aotus New World monkeys: model for studying malaria-induced anemia. Blood. 2002 May;99(10):3863-6.

50 Alves FA. Estudo da suscetibilidade e da vulnerabilidade do primata neotropical Aotus infulatus à infecção pelo Plasmodium falciparum e sua utilização na avaliação pré-clínica de dois antígenos candidatos à vacina antimalárica [dissertação]. Rio de Janeiro: Fundação Oswaldo Cruz; 2003.

51 Alves FA. Desenvolvimento e validação de ferramentas moleculares para análise da resposta imune de primatas Aotus e Saimiri [tese]. Rio de Janeiro: Fundação Oswaldo Cruz; 2009.

52 Alves FA, Souza MT, Gonçalves EC, Schneider MPC, Marinho AM, Muniz JAPC, et al. DNA sequencing of 13 cytokine gene fragments of Aotus infulatus and Saimiri sciureus, two non-human primate models for malaria. Cytokine. 2010 Dec;52(3):151-5.

53 Hensmann M, Kwiatkowski D. Cellular basis of early cytokine response to Plasmodium falciparum. Infect Immun. 2001 Apr;69(4):2364-71. 
54 Artavanis-Tsakonas K, Riley EM. Innate immune response to malaria: rapid induction of IFN- $\gamma$ from human NK cells by live Plasmodium falciparum-infected erythrocytes. J Immunol. 2002 Sep; 169(6):2956-63.

55 Pratt-Riccio LR, Bianco-Jr C, Totino PRR, Perce-Da-Silva DD, Silva LA, Riccio EKP, et al. Antibodies against the Plasmodium falciparum glutamate-rich protein from naturally exposed individuals living in a Brazilian malaria-endemic area can inhibit in vitro parasite growth. Mem Inst Oswaldo Cruz. 2011 Aug;106 Suppl 1:34-43.

56 Carvalho LJM, Alves FA, Bianco Jr C, Oliveira SG, Zanini GM, Soe S, et al. Immunization of Saimiri sciureus monkeys with a recombinant hybrid protein derived from the Plasmodium falciparum antigen glutamate-rich protein and merozoite surface protein 3 can induce partial protection with Freund and Montanide ISA720 adjuvants. Clin Diagn Lab Immunol. 2005 Feb;12(2):242-8.
57 Carvalho LJM, Oliveira SG, Theisen M, Alves FA, Andrade MCR, Zanini GM, et al. Immunization of Saimiri sciureus monkeys with Plasmodium falciparum merozoite surface protein-3 and glutamate-rich protein suggests that protection is related to antibody levels. Scand J Immunol. 2004 Apr;59(4):363-72.

58 Oeuvray C, Bouharoun-Tayoun H, Gras-Masse H, Bottius E, Kaidoh T, Aikawa M, et al. Merozoite surface protein-3: a malaria protein inducing antibodies that promote Plasmodium falciparum killing by cooperation with blood monocytes. Blood. 1994 Sep;84(5):1594-602.

59 Theisen M, Soe S, Jessing SG, Okkels LM, Danielsen S, Oeuvray $C$, et al. Identification of a major B-cell epitope of the Plasmodium falciparum glutamate-rich protein (GLURP), targeted by human antibodies mediating parasite killing. Vaccine. 2000 Sep; 19(2-3):204-12. 